\title{
KR $A S$ MUTATION TESTING IN COLORECTAL CANCER AS AN EXAMPLE OF THE PATHOLOGIST'S ROLE IN PERSONALIZED TARGETED THERAPY: A PRACTICAL APPROACH
}

\author{
Pawee Domagaea ${ }^{1}$, Jolanta Hybiak ${ }^{1}$, Violetta Sulżyc-Bielicka ${ }^{2}$, Cezary Cybulski ${ }^{3}$, \\ JANUSZ RYŚ $S^{4}$, WenANCJUSZ DOMAGAŁA ${ }^{1}$
}

\author{
${ }^{1}$ Department of Pathology, Pomeranian Medical University, Szczecin, Poland \\ 2Department of Clinical Oncology, Pomeranian Medical University, Szczecin, Poland \\ 3 Department of Genetics and Pathology, Pomeranian Medical University, Szczecin, Poland \\ ${ }^{4}$ Department of Tumour Pathology, Centre of Oncology - Maria Skłodowska-Curie Memorial Institute, \\ Kraków Branch, Poland
}

Identifying targets for personalized targeted therapy is the pathologist's domain and a treasure. For decades, pathologists have had to learn, understand, adopt and implement many new laboratory techniques as they arrived on the scene. Pathologists successfully integrate the results of those tests into final pathology reports that were, and still are, the basis of clinical therapeutic decisions. The molecular methods are different but no more difficult to comprehend in the era of "kit procedures". In recent years, the development of targeted therapies has influenced routine practices in pathology laboratories because the use of molecular techniques is required to include clinically useful predictive information in the pathology report. Pathologists have the knowledge and expertise to identify particular gene mutations using the appropriate molecular tests currently available.

This review focuses on the most important recent developments in KRAS mutation testing in metastatic colorectal cancer (CRC), and shows that a pathologist is involved in 10 stages of this procedure. Recent studies have shown that highly sensitive, simple, reliable and rapid assays may significantly improve the identification of CRC patients resistant to anti-EGFR therapy. Thus, direct sequencing does not seem to be an optimal procedure of $K R A S$ testing for clinical purposes. Twelve currently available high-sensitivity diagnostic assays (with the CE-IVD mark) for KRAS mutation testing are briefly described and compared. The suggested pathology report content for somatic mutation tests is described. In conclusion, evidence is presented that sending away paraffin blocks with tumor tissue for $K R A S$ mutation testing may not be in the best interest of patients. Instead, an evidence-based approach indicates that $K R A S$ mutation testing should be performed in pathology departments, only with the use of CE-IVD/FDA-approved KRAS tests, and with the obligatory, periodic participation in the KRAS EQA scheme organized by the European Society of Pathology as an independent international body.

Key words: KRAS, EGFR, colorectal cancer, molecular pathology, targeted therapy. 


\section{Introduction}

For decades, pathologists have had to successfully learn, understand, adopt and implement many laboratory techniques as they arrived on the scene (e.g., histological, cytological, histochemical, ultrastructural and immunohistochemical techniques). Pathologists were able to integrate the results of those tests into final pathology reports that were, and are, the basis of clinical therapeutic decisions. This does not mean that pathologists had to perform those laboratory procedures themselves; rather, they had to understand them and know how and when to apply them. But, who performed the tests? Biologists employed in pathology laboratories performed the tests. We do not see the basic difference with the emergence of new molecular methods. Again, with the advent of molecular methods pathologists have to understand them and know how and when to apply them. In many pathology laboratories this understanding has already occurred. In fact, a continuing education is the first commandment for a physician in general and the pathologist in particular. Such education may be painful for some, but it is necessary. Of course, the integration of new methodology has always been a team endeavor; specifically, biologists performed the procedures and pathologists integrated the results to formulate diagnoses. In our view, molecular methods are different but they are not more difficult to comprehend than previous methods. Molecular methods can be understood, adopted and implemented by an average pathologist who can easily learn how to integrate the results into a pathology report, provided that appropriate training programs in genomic medicine are organized during the pathology residency. Molecular biology is not a hermetic, mysterious knowledge that one cannot master. In fact, clinically useful molecular biology techniques are not especially difficult to learn because nowadays many molecular procedures have been standardized and greatly simplified. To obtain proper results, just one major requirement has to be fulfilled, namely faithful adherence to the detailed manufacturer's instructions. It is obvious that pathologists have to cooperate with the molecular biologists employed in their departments. However, in our view, it is equally important that pathologists learn the basics of molecular biology necessary to implement molecular biology procedures in their laboratories. Therefore, continuous efforts should be made in this respect during the pathology residency period, as well as afterward, in the process of continuing education.

\section{Pathological diagnosis}

In recent years, the development of targeted therapies has influenced the routine practices used in surgical pathology laboratories. Previously, cancer therapy was based on the histological type and grade of a tumor as well as the clinical stage of the disease. With the advent of targeted therapy, specific predictive information is sought. The results of an assessment of several predictive markers (mutations, amplifications, and proteins) have to be incorporated into the traditional pathological diagnosis because not all patients derive clinical benefit from targeted therapy. A classic example of targeted therapies is anti-estrogen therapy, which is successful only in patients with breast cancer cells expressing estrogen/progesterone receptors. Thus, a pathologist must provide a specific diagnosis and is expected to assess predictive markers so that patients most likely to respond to targeted therapies may be identified. Furthermore, when several protein/molecular targets are identified in a particular tumor, the development of personalized therapy (in the strict sense of the word) is possible because several therapeutic options may be revealed that are available only for a given patient [1].

\section{Take-home messages:}

- KRAS mutation status has emerged as an important predictive marker for anti-EGFR therapy in patients with $\mathrm{mCRC}$

- A pathologist is involved in $K R A S$ testing in 10 stages of the procedure

- Microdissection should be performed in every case to obtain tissue enriched with tumor cells for KRAS mutation testing

- The sensitivity of direct sequencing for analysis of KRAS mutations in FFPE tumor samples seems to be too low to enable its use as a routine clinical test

- The final choice of the CE-IVD-marked KRAS mutation test is largely dependent on the laboratory equipment, experience and cost of the test

- KRAS mutation testing should be performed in pathology departments, only with CE-IVD/FDAapproved $K R A S$ tests, and with obligatory, periodic participation in the KRAS EQA scheme organized by the European Society of Pathology as an independent international body 
Currently, predictive immunohistochemical and molecular diagnostic tests identify suitable patients for targeted therapy. Therefore, to include predictive information in the pathology report, immunohistochemistry and molecular techniques are required. This simply means that to provide oncologists with meaningful predictive information (incorporated into the pathological diagnosis), contemporary pathology departments should be equipped with appropriate laboratories where molecular techniques necessary to reveal targets for implementation of targeted therapy can be performed, similar to the setup of contemporary immunohistochemical laboratories. Molecular tests can also be performed outside the pathology department in certified molecular laboratories. However, in such situations:

1) there are unnecessary delays associated with the need to send sections or paraffin blocks, which is not in the best interest of patients;

2) molecular biologists who perform a test in a molecular laboratory may be unfamiliar with the latest clinical data related to the molecular alterations tested and the intricacies of pathological, clinical and therapeutic significance of particular tests;

3) responsibility for the final diagnosis is blurred;

4) the pathologist has a curious role of a distributor of paraffin blocks/sections and a messenger of predictive information between a molecular biologist and a physician. At best, this role is that of a coordinator rather than of a generator of the vital final pathological diagnosis with predictive information.

It may be helpful here to define the meaning of the term "pathological diagnosis" of tumors. A pathological diagnosis (report) is obtained on the basis of microscopic analysis of tissue and/or cells TOGETHER WITH additional tests (e.g., histochemical, immunohistochemical and, molecular tests) and clinical data, to provide information concerning histological type of a tumor AND predictive/prognostic data.

\section{KRAS mutations}

There are three $R A S$ genes in the human genome; $K R A S, H R A S$ and NRAS. Approximately $15-20 \%$ of all human neoplasms contain $R A S$ mutations. Mutations in the KRAS gene are detected in $35-45 \%$ of CRCs [2-8], whereas $N R A S$ and $H R A S$ mutations are only found in $1-3 \%$ of CRCs. KRAS mutations are frequent in pancreatic, colorectal, biliary tract, and lung cancers. The most common KRAS mutations in CRCs are found in codons 12 ( $\sim 77 \%$ of mutations) and $13(\sim 20 \%$ of mutations) in exon 2 of the gene. Much less frequent are mutations in codons $61(1 \%)$ and $146(0.5 \%)$ (data from the COSMIC database v60) [9]. Somatic missense mutations in codon 12 of the KRAS gene, resulting in a single amino acid substitution (p.Gly12Val), are the most common abnormalities in CRCs.

\section{RAS/EGFR signaling pathway}

The KRAS gene encodes a small GTPase protein (G protein) that functions downstream of EGFR-induced cell signaling, and participates in the activation of important oncogenic signaling pathways. The RAS protein is a key element of the RAS-MAPK intracellular signaling pathway, which is triggered by EGFR tyrosine phosphorylation of the intracellular domain of the receptor. This triggering results in the activation of several other signaling pathways that control gene transcription, cell proliferation, apoptosis, angiogenesis, invasion and migration [10]. Therefore, the EGFR signaling system is regarded as crucial to the regulation of the growth, proliferation and malignant transformation of epithelial cells.

RAS proteins, which act as signal transducers, normally cycle between active (RAS-GTP) and inactive (RAS-GDP) conformations. RAS proteins are activated by guanine nucleotide exchange factors (GEFs) and inactivated when RAS-GTP is hydrolyzed to RAS-GDP by GTPase-activating proteins (GAPs). In normal cells, the activities of GEFs and GAPs are tightly controlled and the RAS-GTP level is kept in check. Mutations in $R A S$ result in markedly reduced the intrinsic GTPase activity of RAS proteins and make these proteins resistant to the GAPs. Thus, mutated RAS proteins permanently remain in the RAS-GTP active form and continuously activate signaling pathways without stimulation of the HER family of cell surface receptors [11-14]. Such an activating mutation may induce an oncogenic transformation or confer resistance (insensitivity) to anti-EGFR antibody therapies due to permanent, EGFR-independent activation of both the PI3K/AKT and MAPK pathways.

\section{Mutations in $K R A S$ as predictive markers for anti-EGFR treatment in patients with metastatic colorectal cancer}

Given the EGFR independent activation of $K R A S$ it is not surprising that, anti-EGFR antibodies will not be effective in patients with metastatic CRC ( $\mathrm{mCRC}$ ) with a KRAS mutation. Indeed, an association of KRAS mutations in CRC with resistance to anti-EGFR monoclonal therapy was reported $[15,16]$. These results were subsequently confirmed in independent retrospective studies $[17,18]$. Finally, supportive evidence of predictive significance of $K R A S$ mutations for antiEGFR treatment of $\mathrm{mCRC}$ was obtained from phase II and III clinical trials of the anti-EGFR monoclonal antibodies cetuximab and panitumumab used either as monotherapy or in combination with chemotherapy in patients with mCRC (references in [19]). For ex- 
ample, single-agent, randomized, controlled trials with cetuximab [20] and panitumumab [21] revealed no benefit from these anti-EGFR therapies in $K R A S$-mutant mCRCs patients. In a study of secondor third-line treatment of $\mathrm{mCRC}$ patients with cetuximab, the statistically significant differences between the antibody arm and control arm were $12.8 \%$ vs. $0 \%$ for response rate, 3.7 months vs. 1.9 months for progression-free survival and 9.5 months vs. 4.8 months for median overall survival [20]. In April 2009, based on an analysis of five randomized controlled trials of cetuximab or panitumumab and five single-arm retrospective studies, the following provisional clinical opinion of the American Society of Clinical Oncology was issued: “....all patients with mCRC who are candidates for anti-EGFR antibody therapy should have their tumor tested for KRAS mutations in a CLIA-accredited laboratory. If a $K R A S$ mutation in codon 12 or 13 is detected, patients with mCRC should not receive anti-EGFR antibody therapy as part of their treatment" [19]. Both the European Medicines Agency (EMEA) and the U.S. Food and Drug Administration (FDA) approved the use of cetuximab and panitumumab for treatment in patients with wild-type $K R A S$ mCRC. However, there are differences in those approvals. The EMEA approved both drugs for the treatment of patients with wild-type $K R A S \mathrm{mCRC}$ in 2007 without mentioning methodology or the exact mutations to be tested. In contrast, the FDA specified the testing for mutations in codon 12 or 13 of $K R A S$ in their recommendations issued in 2009 and, in addition, required that two conditions be met: validation of a single assay for mutation detection and reassessment of all randomized clinical trials with this assay. In July 2012, the FDA approved the TheraScreen kit to be sold as a companion diagnostic test for cetuximab. Furthermore, the FDA has additionally approved the use of cetuximab in combination with FOLFIRI (5-fluorouracil, irinotecan, leucovorin) as a first-line treatment in patients with $\mathrm{mCRC}$ and EGFRexpressing and wild-type $K R A S$ tumors. Thus, $K R A S$ mutation status has emerged as an important predictive marker for anti-EGFR antibody therapy in patients with mCRC. The clinical trial data briefly summarized above strongly support the recommendation that patients whose CRCs do not have KRAS mutations should be treated with anti-EGFR monoclonal antibodies, and that those with KRAS mutations should not be treated with this therapy. The results described above pertain to KRAS mutations in codons 12 and 13 of exon 2 . Recent reports suggest that although rare $K R A S$ exon 3 mutations may also be associated with a lack of response to anti-EGFR monoclonal antibodies [22]. However, the examination of $K R A S$ mutations in exon 3 does not significantly improve the identification of non-responding mCRC patients.
Thus, the presence of $K R A S$ mutations has become widely accepted as a negative predictive marker for antiEGFR monoclonal antibody therapy in MCRC patients. However, in the future, the presence of these mutations may also become a positive predictive marker for therapies based on the inhibition of KRAS activation or the inhibition of alternative downstream kinases in $K R A S$-mutant mCRC patients. There are several ongoing preclinical studies and clinical trials utilizing different therapeutic approaches in this respect, e.g., BRAF inhibitors in $B R A F$-mutant mCRCs, MEK inhibitors, farnesyltransferase inhibitors, and SFK inhibitors (e.g., dasatinib), which may sensitize $K R A S$-mutant mCRCs to cetuximab (dual kinase inhibition) [23]. These new therapeutic approaches only underscore the clinical importance of $K R A S$ testing for the targeted therapy of patients with mCRCs.

Key role of the pathologist in the assessment of therapeutic targets in general and KRAS mutation testing in particular

A pathologist is involved in KRAS testing in 10 stages of the procedure.

1) A pathologist decides on the method of tumor tissue collection for KRAS testing prior to DNA extraction. There is no consensus recommendation for this step, although general recommendations have been made (by CAP [24] and NCCN [25]) regarding the process of tissue collection. From a practical point of view, buffered formalin-fixed, paraffin-embedded (FFPE) tumor tissue is most commonly used for $K R A S$ testing. Testing may also be performed on fresh tissue stored in a preservative solution (e.g., RNAlater [Ambion]), rapidly frozen and stored tissue [19] or formalin-free fixed tissue [26, 27].

2) A pathologist identifies sources of tumor material for the assessment of KRAS mutation status. According to the National Comprehensive Cancer Network's (NCCN) clinical practice guidelines [25], either primary or metastatic tumors can be used for $K R A S$ testing. Based on results showing a high level of concordance between KRAS mutation status in primary vs. metastatic CRCs $[28,29]$ and observations indicating that KRAS mutations may occur early in the progression of CRC, there is a consensus opinion that in metastatic disease KRAS testing of the primary CRC provides conclusive results. Because archival paraffin blocks from the primary tumor are available in the majority of cases of metastatic disease, there is no need for biopsy of a metastatic tumor. When a patient presents with metastasis at the initial diagnosis, a metastatic tumor biopsy may be used for the KRAS test. When post-radiochemotherapy low tumor cellularity is found in a specimen, pre-treatment biopsies repre- 
sent the most cost-effective option for reliable KRAS genotyping [30].

3) A patbologist is responsible for the selection and evaluation of the tumor tissue block. A pathologist makes the judgment as to whether there is sufficient quantity and quality of tumor material to be used in DNA extraction for KRAS testing (see below). The amount of tumor tissue in the specimen and the general quality of the collected tissue and extracted DNA have important implications for the accuracy and sensitivity of the KRAS testing method used [31].

4) $A$ patbologist is responsible for tumor cell enrichment in a target tissue sample. To increase the sensitivity of mutation testing, several methods may be employed to enrich the tested sample in tumor cells, e.g., macrodissection, manual microdissection or laser microdissection (see below). All of these techniques require the user to be familiar with microscopy and histopathology [32].

5) A pathologist chooses the method to be used for KRAS testing in the laboratory. To make a wellinformed decision regarding the testing method to be used, the pathologist should consult with a molecular biologist and take into consideration the DNA amount and quality required, time to obtain results, accuracy, sensitivity and the cost of the preferred method (see below and Table I). Each method has its advantages and disadvantages. However, although traditional Sanger sequencing detects all clinicallyimportant $K R A S$ mutations, its sensitivity is too low to be used as a routine clinical test (mutant alleles must be present in at least $30-40 \%$ of cells for reproducible detection) $[2,33-35]$. To the best of our knowledge, there are currently 12 highly sensitive, simple, rapid CE-IVD-marked diagnostic assays for KRAS mutations (see below and Table I). The minimal requirements that a $K R A S$ test should satisfy include: a specificity of $100 \%$ and a mutation detection sensitivity of between 95 and $99 \%$ [36]. It is clear that increasing the sensitivity of the methods used to detect KRAS mutations can greatly improve predictions of resistance to anti-EGFR treatment [37-41]. Therefore, high sensitivity of the method is a key issue. Due to the intratumoral heterogeneity of KRAS mutations [42-45], clones bearing KRAS mutations may be undetected by direct sequencing $[37,41]$, and tumor cells from these clones may exhibit an increased propensity for distant metastases [37].

6) A patbologist, together with a molecular biologist, actively participates in the laboratory procedure for KRAS testing. Pathologists should be aware of the types of procedures used and their pros and cons, and specifically, they should be familiar with the details of the procedures used in his or her department. Test data should be analyzed and discussed

Table I. Comparison of KRAS genotypes detected by CE-IVD-marked commercial kits, frequency of their appearance in CRCs and cost per sample. Green boxes highlight mutations that are detected by a particular kit

\begin{tabular}{|c|c|c|c|c|c|c|c|c|c|}
\hline \multirow{2}{*}{$\begin{array}{l}\text { CE-IVD } \\
K R A S \text { KIT }\end{array}$} & \multirow{2}{*}{$\begin{array}{c}\text { APPROX. } \\
\text { COST PER } \\
\text { SAMPLE } \\
(\text { USD) })^{\mathrm{a}}\end{array}$} & \multicolumn{8}{|c|}{ A.A. MUTATIONS AND THEIR FREQUENCY IN CRC $(\%)^{\mathrm{b}}$} \\
\hline & & $\begin{array}{c}\text { G12A, G12C } \\
\text { G12D, G12R } \\
\text { G12S, G12V } \\
\text { G13D } \\
(96.2)\end{array}$ & $\begin{array}{c}\text { G13C } \\
(0.5)\end{array}$ & $\begin{array}{c}\text { G13S } \\
\text { G13R } \\
(0.3)\end{array}$ & $\begin{array}{c}\text { G13A } \\
\text { G13V } \\
\text { G13I } \\
\text { G12F } \\
(0.3)\end{array}$ & $\begin{array}{c}\text { Q61H } \\
\text { (CAT) } \\
\text { Q61H } \\
(\text { CAC) } \\
(0.5)\end{array}$ & $\begin{array}{c}\text { Q61L } \\
\text { Q61R } \\
(0.3)\end{array}$ & $\begin{array}{l}\text { Q61K } \\
\text { Q61E } \\
\text { Q61P } \\
(0.1)\end{array}$ & Other \\
\hline TheraScreen PCR & 210 & & & & & & & & \\
\hline AmoyDx & 117 & & & & & & & & \\
\hline PNAClamp & 70 & & & & & & & & \\
\hline RealQuality & 50 & & & & & & & & \\
\hline EntroGen & 77 & & & & & & & & \\
\hline LightMix & 57 & & & & & & & & d \\
\hline StripAssay & 77 & & & & & & & & e \\
\hline Hybcell plex $A^{c}$ & 124 & & & & & & & & \\
\hline Devyser $^{\mathrm{C}}$ & 40 & & & & & & & & \\
\hline Surveyor $^{\mathrm{C}}$ & 26 & & & & & & & & $\mathrm{f}$ \\
\hline Cobas $^{c}$ & 81 & & & & & & & & \\
\hline TheraScreen Pyro $^{c}$ & 124 & & & & & & & & $\mathrm{~g}$ \\
\hline
\end{tabular}

${ }^{a}$ According to price quotes (net) available in Poland (August 2012). Cost calculated per sample when the maximum number of cases is tested in a batch (the optimum circumstances). This is only the kit cost per sample and does not include the costs of shipping, DNA isolation and quantification, repeat tests or labor cost; ${ }^{\circ}$ The mutation frequency (CRCs only) was obtained from the COSMIC database v60; ' Requires equipment other than that used for real-time PCR; ${ }^{\circ} G 12 T ;{ }^{e} G 12 I$ and G12L; ${ }^{\circ}$ other mutations in exon $2{ }^{8}{ }^{\circ}$ ther mutations in codons 12,13 , and 61 
Table II. Pathology report content for a somatic mutation test. A checklist

\begin{tabular}{|c|}
\hline GENERAL INFORMATION \\
\hline$\square$ Report title 1 \\
\hline$\square$ Name and address of the reporting institution \\
\hline $\begin{array}{l}\text { Name and address of the requesting institution } \\
\text { and name of the requesting oncologist }\end{array}$ \\
\hline $\begin{array}{l}\text { Date of the request form (if material comes from } \\
\text { the same pathology department where mutation test } \\
\text { will be performed) or date of arrival of the sample } \\
\text { with the request form }\end{array}$ \\
\hline$\square$ Date of the report \\
\hline$\square$ Own reference number of mutation test \\
\hline $\begin{array}{l}\text { Total number of pages and page numbers (e.g., } 1 \text { of } 2 \text { ) } \\
C P T \text { codes }^{2} \\
\text { Cite references for report facts }\end{array}$ \\
\hline PATIENT INFORMATION \\
\hline$\square$ Name and age \\
\hline $\begin{array}{l}\text { ID number or date of birth } \\
\text { Short clinical history }\end{array}$ \\
\hline SAMPLE INFORMATION \\
\hline$\square$ Sample number \\
\hline $\begin{array}{l}\text { Nature of the sample (e.g., FFPE } 3 \text {, fresh frozen, } \\
\text { or biopsy) }\end{array}$ \\
\hline$\square$ Tumor origin (e.g., primary, metastatic, or recurrent) \\
\hline $\begin{array}{l}\text { Sample adequacy, e.g., satisfactory for evaluation } \\
\text { or unsatisfactory for evaluation (specify reason) } \\
\text { Percentage of tumor cells } 4\end{array}$ \\
\hline METHODS USED \\
\hline $\begin{array}{l}\text { Identification of the best block with the highest } \\
\text { percentage of tumor cells: yes or no }\end{array}$ \\
\hline $\begin{array}{l}\text { Method of tumor cell enrichment: macrodissection, } \\
\text { microdissection, or none }\end{array}$ \\
\hline$\square$ Method of DNA isolation \\
\hline Method of genotyping \\
\hline$>$ Name of the diagnostic kit (CE-IVD/FDA-approved) \\
\hline$>$ Sensitivity of the method \\
\hline$>$ List of mutations that were tested 5 \\
\hline
\end{tabular}

\begin{tabular}{l}
\hline RESULT \\
\hline$\square$ Genotype $^{5}$ \\
$\square$ Interpretation regarding the treatment $^{6}$ \\
$\square$ Comments $^{7}$ (if applicable)
\end{tabular}

\begin{tabular}{l}
\hline RESPONSIBILITY \\
\hline Signatures 8 and printed names of the molecular \\
biologist and pathologist involved in performing \\
the test and interpreting the results \\
\hline The optional items in each section are shown (without a checkbox) in italics. \\
${ }^{1}$ Should include the name of the tested gene (s) clearly distinguished from the rest \\
of the report; ${ }^{2}$ Current Procedural Terminology (CPT) codes document the analytical \\
and interpretative procedures that are performed in the laboratory; ${ }^{3}$ Formalin buffered \\
or not; ${ }^{4}$ If the test was performed without microdissection andlor a low sensitivity \\
method was used; ${ }^{5}$ Nomenclature according to HGVS guidelines; ${ }^{6}$ Example: presence \\
of KRAS mutation indicates likely resistance to anti-EGFR therapy; ${ }^{7}$ Examples: \\
recommendations for further testing; condition of a specimen that may limit the adequacy \\
of testing; reason why a specimen was rejected or not processed to completion; if the report \\
is an amended or addendum report, a description of the changes or updates; ${ }^{8}$ Reports \\
may be signed electronically
\end{tabular}

jointly by the pathologist and molecular biologist. The pathologist is also involved in the continuous review process of new technologies and publications on $K R A S$ mutation testing.

7) $A$ pathologist writes the results of a KRAS test in a special report that is understandable to the oncologists. The KRAS mutation report, similar to the report of any molecular test of clinical significance, should contain items listed in Table II $\{19,36,46-54\}$. If a mutation is identified, the affected codon and the specific change should be reported. This is an important aspect of the report because recommendations for treatment eligibility are continuously evolving.

8) A patbologist provides the interpretation of results in terms of their predictive significance. The pathologist should report the results of $K R A S$ testing, as well as their therapeutic significance, in the particular clinical context of a patient. The interpretation of results should be clear and accurate in view of the findings described above (in the paragraph "Mutations in KRAS as predictive markers for anti-EGFR treatment in patients with metastatic colorectal cancer") and the most recent literature data. The interpretation of the genomic information should assist a physician in therapeutic decisionmaking, i.e., to help predict which patients are most likely to benefit from anti-EGFR monoclonal antibody treatment. Specifically, it should be noted that a wild-type result does not rule out the presence of rare mutations not tested by the assay used. Moreover, it should be added that not all patients with wild-type KRAS cancers will respond to antiEGFR antibody therapies, the predictive information of the KRAS test applies only to anti-EGFR monoclonal antibody therapy and not to other types of therapies, and KRAS mutation tests in metastatic and corresponding primary cancers are discordant in less than $5 \%$ of cases [55].

9) A patbologist is responsible for the turnaround time of the report. A recent survey of KRAS testing revealed that test results were available within 15 days for $82 \%, 51 \%$ and $98 \%$ of tested patients in Europe, Latin America and Asia, respectively [56]. In another study, the results were obtained with a mean delay of 33 days [57]. Although it seems that a delay of 10-14 working days is acceptable [47], an effort should be made to make the report available in a shorter time (one has to keep in mind that a patient with metastatic CRC is waiting for this test and the therapeutic decision). The turnaround time can be substantially shortened if the whole procedure is performed in the pathology department that provided the histopathological diagnosis of CRC. In fact, in our experience, KRAS mutation test can be done and the report issued in three working days, starting from the date on which the test was requested. 
10) A patbologist is responsible for the implementation of an external quality assurance (EQA) program in the molecular diagnostic laboratory of the patbology department in which be or she works. We share the well-founded opinion that evidence-based approaches require EQA programs for $K R A S$ testing (see below).

In summary, the pathologists looking down the microscope remain the final decision makers [58]. They may seek advice from molecular biologists and oncologists but the final diagnostic decision and the responsibility is theirs. Certainly, "...genomic analysis in the absence of pathologic assessment risks the generation of meaningless results" [59]. Currently a pathology report that is meaningful to the oncologist as well as to the patient includes a diagnostic algorithm integrating conventional histopathology with immunohistochemistry [60] and disease-specific molecular tests.

\section{$K R A S$ testing as a routine test necessary to provide predictive information in pathology reports of colorectal cancer}

Because the assessment of KRAS mutations has become an important aspect of management of $\mathrm{mCRC}$ patients, there is an urgent need to establish and agree on the best laboratory procedures to ensure accurate assessment of KRAS status. A routine predictive test should be relatively simple to perform, fast, reliable (in terms of sensitivity and specificity) and not too expensive. Contemporary somatic mutation testing has taken the form of a "kit procedure". It is simple, fast and reliable, provided that a test that is approved by the appropriate national or international agencies is used, the producer's protocol is rigorously followed, and an EQA program is implemented by the laboratory. Below, we briefly describe the most important aspects of $K R A S$ mutation testing procedures in which FFPE CRC tissue is used. Currently, FFPE tissue is widely used in KRAS testing, but fresh-frozen tissue or cytological material can also be clinically useful.

\section{Selection and evaluation of the tumor tissue block}

Although somatic mutation analysis does not require a pure cell population, tumor cellularity is a critical issue. A pathologist responsible for selecting a paraffin block for molecular tests should choose one that has the greatest percentage of invasive cancer cells and avoid blocks with many lymphocytes, necrosis or extracellular mucin. These factors can diminish the sensitivity of the technique, particularly if direct sequencing is used [61]. It has to be kept in mind that genotyping is performed on genomic DNA of both tumor cells and benign stromal cells of tumor microenvironment. Thus, sections for the test should be taken from blocks containing tumor tissue enriched with intact cancer cell nuclei. International guidelines suggest that the specimen should contain a cancer cell percentage of at least $70 \%$ if a low-sensitivity technique, such as direct sequencing of the PCR product, is used [46]. In any case, the specimen should contain at least 100 cancer cells [62].

Evaluation of the tumor's contents is a subjective procedure that depends on both the region selected and the assessment of the ratio between the cancer cells and normal nucleated cells. High inter-observer variability has been reported in the estimation of the percentage of cancer cells in hematoxylin and eosin (HE) stained sections. An EQA study involving 13 experienced laboratories revealed large differences in the estimates of this percentage in the same samples, varying from 9 to $90 \%$ or from 32 to $95 \%$. There was no consistent pattern in the estimates between different laboratories [31, 47, 63]. These differences may be partially explained by incorrect measurement of the percentage of the sample area that is tumor, instead of the percentage of nuclei that are in the tumor [64], which is more difficult to measure with the naked eye. Furthermore, large differences in the diameter of tumor cell nuclei and the nuclei of the neighboring benign stromal cells make the estimation of tumor DNA content difficult and imprecise, and usually the contribution of normal cell nuclei to total DNA content is underestimated. Thus, the histological assessment of tumor cell percentage can serve only as a very rough estimate of tumor DNA content in the corresponding extract $[65,66]$. For the above reasons, tumor cell enrichment is necessary for genotyping with FFPE tissue.

\section{Macrodissection and microdissection}

The percentage of cancer cells in the specimen and the general quality of the collected tissue and extracted DNA have important implications for the accuracy and sensitivity of the KRAS testing method used [31]. The target tissue will always contain some normal cells within the tumor microenvironment (e.g., lymphocytes, macrophages, endothelial cells, and fibroblasts). To increase the sensitivity of mutation testing, several methods may be employed to achieve cancer cell enrichment in tested material, e.g., macrodissection, laser microdissection, and manual microdissection.

Macrodissection. In this method, HE-stained slides are examined and the enriched tumor cell area is marked by a pathologist on a HE-stained slide that will be used as a template for macroscopic dissection (without the microscope) of the consecutive slide(s). The area corresponding to the area marked on the template HE slide is scratched off using a sterile, single-use scalpel. 
Laser microdissection. This is the most accurate technique to separate tumor cells from benign stromal cells. However, it is time-consuming and requires very expensive equipment. Therefore, it cannot be recommended for routine use in every case. In our experience and that of others [67], in some cases where tumor cellularity is low or tumor cells are dispersed (e.g., small biopsy, cytology specimens, or post-radiochemotherapy samples), isolation by laser microdissection results in a purer population of tumor cells for mutation detection and is a more sensitive method compared with other methods.

Manual microdissection. This simple technique is more accurate than macrodissection and less meticulous than laser microdissection. It can be performed on unstained tissue, but the best results are obtained using stained tissue sections, enabling the procurement of tissue compartments (even as small as $1 \mathrm{~mm}^{2}$ ) much faster than laser microdissection and more accurately than macrodissection [68]. For manual microdissection, the tumor area is dissected by a pathologist under a light microscope (standard or inverted). The compartments without cancer cells are removed with a scalpel or injection needle, and the remaining tissue fragments (containing nearly all cancer cells) are removed (scratched) into a test tube for further treatment (one can also place the cancer cells into a test tube first). Almost any histological staining (e.g., cresyl violet, methyl green, methylene blue, toluidine blue, and nuclear fast red) can be used to visualize nuclei in sections selected for DNA or RNA molecular analysis, because the staining does not interfere with DNA and RNA testing [69]. Although some older studies reported that HE staining inhibited DNA amplification by PCR $[70,71]$, recently published data $[69,72,73]$ provide no evidence for the interference of HE staining with DNA testing. These results suggest that DNA from HE-stained sections can be effectively used for routine DNA testing, which is especially important when only HE-stained slides, and not tissue blocks, are available. Then, after the HE slides are scanned, somatic mutations can be directly tested from routinely stained HE sections.

Manual microdissection is a powerful tool to enrich the analyzed sample with tumor cells. Recent research on the reported clinical benefit associated with highly sensitive KRAS detection methods suggests that manual microdissection will become an indispensable routine method to obtain tissue enriched with tumor cells for the analysis of somatic mutations. In this approach, subjective counting of the relative frequency of neoplastic cells in a tissue sample may be avoided because manual microdissection, together with highly sensitive diagnostic KRAS tests, assures a high level of sensitivity and repeatability. Thus, in our opinion, manual microdissection should be performed in every case to obtain tumor tissue of the appropriate quality and quantity for KRAS mutation testing.

\section{DNA isolation}

DNA quality is one of the most important factors when performing DNA mutation assays in FFPE tissue; therefore, the DNA extraction methodology is critical. The formation of DNA-protein cross-links due to the formaldehyde solution leads to nucleic acid fragmentation but at the same time, nucleases are deactivated (- a stabilizing effect). Thus, while molecular templates from FFPE tissue are of inferior quality compared with those from fresh-frozen tissue, they may still be useful for nucleic acid assessment with recently developed methods (even for microarray profiling and wide genome scans), and results from FFPE tissue are largely comparable with data obtained from fresh-frozen material $\{65,74-76]$. The main advantage of using FFPE tissue for molecular analyses in cancer research is the possibility of achieving an accurate correlation of the results with tissue histology and with long-term follow-up data. This ability is especially important in rare subtypes or subpopulations of cancers. Another advantage is the availability of FFPE tumor tissue for the assessment of predictive markers when new targeted therapies are developed in the future.

There are plenty of "in-house" methods and commercially available kits specially designed for DNA isolation from FFPE tissue. The aim of these methods is to increase the DNA yield from FFPE tissue, and they involve steps to reverse modification of nucleic acids by formaldehyde. The highest amount of DNA was obtained using the phenol-chloroform extraction method $[73,77-79]$ or the WaxFree DNA kit (TrimGen, Sparks, MD, USA) [78, 79]. However, the quality of the real-time PCR reactions is quite often compromised when using isolates with increased quantities of DNA [78]. Furthermore, spectrophotometric analysis revealed that DNA extracted with the use of the WaxFree DNA kit was of poorer quality compared with that obtained with the use of phenol-chloroform, silica-based columns (QIAamp DNA FFPE Tissue kit, Qiagen, Hilden, Germany) or rapid glass-fiber filters (RecoverAll kit, Ambion, Austin, TX, USA) [79]. Munoz-Cadavid et al. [80] recently evaluated the extraction of high-quality DNA from FFPE tissue in 5 commercial kits and found that the best results were achieved with the TaKaRa Dexpat Kit (Takara Bio, Shiga, Japan) and the QIAamp DNA FFPE Tissue Kit. The Qiagen extraction kit was the most popular DNA extraction method for FFPE tissue in the European Society of Pathology (ESP) KRAS EQA program [47].

DNA obtained from FFPE samples that allow the amplification of $300 \mathrm{bp}$ is considered to be goodquality DNA and can be used for many molecular tests [81]. For tests that require a standardized input of DNA (e.g., multiplex PCR, MLPA, and array-CGH), isolation methods based on silica columns should be recommended. For general molecular tests (e.g., mutations 
and translocations), a simple, rapid and less expensive protocol for DNA isolation (without precipitation or purification) may be sufficient [81-83].

\section{Assessment of DNA quality and quantity}

Widely used methods based on measurements of UV absorbance do not always allow for an assessment of the availability of a material for molecular tests. Common biological contaminants of extracted DNA such as proteins, RNA, and chaotropic salts from extraction procedures can increase the spectrophotometric estimation of DNA concentration [84]. Imprecise measurements may be particularly harmful when further molecular analysis requires the precise assessment of DNA content in the material studied.

Therefore, for the assessment of the quality of DNA extracted from FFPE tissue that is to be used for molecular tests, methods based on DNA-binding dyes fluorescence, real-time PCR DNA amplification or PCR with agarose gel electrophoresis are more useful than spectrophotometric analysis. The main advantage of real-time PCR-based analysis is the ability to assess how much of the available nucleic acid sample is amplifiable. Drawbacks of this method include the expensive proprietary reagents, primers, and probes needed to perform the assays, the lengthy assay time, and the fact that sample volume has to be expanded [85].

Fluorometric measurement of DNA concentration has gained popularity because it is simple and much more sensitive than absorbance measurements [86]. Fluorometric analysis is not as accurate as real-time PCR, but it is much faster, less expensive and simpler; therefore, it appears to be the optimal approach to the quantification of DNA for molecular analysis of FFPE tissue.

Commercially available real-time quantitative PCR kits for clinical KRAS mutation analysis of FFPE tissue as a better alternative to direct sequencing

Several molecular techniques characterized by different sensitivities, specificities and complexities are currently used in research and clinical studies for the detection of KRAS mutations in FFPE tumor samples. Some techniques require expensive equipment and reagents, whereas other methods can be easily adapted for use in molecular laboratories of departments of pathology without the need for additional machines [87, 88]. Until recently, the most widely available methods for KRAS testing were Sanger sequencing and a variety of "in-house" developed laboratory tests. However, these methods are subject to great inter- and intra-laboratory variability and are not always prone to adequate Quality Control schemes that ensure reproducibility of results [89].
In general, the advantage of sequencing-based methods is the ability to detect all clinically important $K R A S$ mutations. However, direct sequencing has several limitations: (1) it is time consuming and labor intensive; (2) interpretation is subjective if the signal/noise ratio is low; and (3) it has low sensitivity compared with other methods. A mutant allele percentage of more than 5 to $10 \%$ is required for detection of mutant tumor cells in pyrosequencing, and a percentage of 30 to $40 \%$ is needed for Sanger sequencing [33, 34, 61, 90]. The detection of mutations by direct sequencing of cytological specimens, small tumor biopsies or tumors containing a high percentage of non-neoplastic cells, may lead to false-negative results [88]. Bando et al. [2] suggested, on the basis of their experience and literature data, that direct sequencing should be discarded as the method of choice in clinical KRAS testing because with this method, approximately $25 \%$ of patients selected for anti-EGFR therapy will not receive any benefit. Thus, the sensitivity of direct sequencing seems to be too low to be used as a routine clinical test for the analysis of $K R A S$ mutations in FFPE tumor samples.

The development of commercial real-time quantitative PCR assays offers a useful alternative because they are simple, labor-saving (in our experience the procedure takes about $3 \mathrm{~h}$ ) and more sensitive than direct sequencing $[2,37-41,61,88,91-100]$. Furthermore, because they avoid post-PCR handling, the risks of contamination and generation of false-positive results are greatly reduced [101]. Real-time PCR methods yield informative results even in cases with very fragmented DNA, whereas only samples with relatively well-preserved DNA can be accurately analyzed with direct sequencing [65]. The per-sample cost of mutation test with clinically validated methods (CE-IVDmarked) is significantly higher compared with the persample cost using direct sequencing. However, costs of labor, assay development and validation of the method are not included in the assessments of the sequencing method. Moreover, basic equipment for realtime quantitative PCR tests is less expensive (than that for sequencing), and the molecular tests can be performed in most pathology departments with molecular diagnostic laboratories with real-time PCR machines.

\section{Clinical significance of high-sensitivity $K R A S$ testing}

In some CRCs, KRAS mutations may be present in only a small subset of tumor cells (clonal heterogeneity). The failure to find such mutated clones that may be associated with treatment resistance, substantially limits the ability to predict treatment response $[41,91$, 102].

Recent studies have shown that highly sensitive, simple, reliable and rapid assays may significantly improve the identification of $\mathrm{CRC}$ patients resistant to anti-EGFR 
therapy. With such techniques, it is possible to detect $K R A S$ mutations in a subset of tumors that seem to be wild-type when tested with direct sequencing. Using high-sensitivity methods, Molinari et al. [37] identified up to $11 \%$ additional KRAS mutations compared with direct sequencing, and Malapelle $e t$ al. identified $8 \%$ more KRAS mutations in patients not responding to cetuximab. Similarly, it has been reported that KRAS mutation testing by highly-sensitive methods and quality-controlled $K R A S$ assays, may more closely correlate with the clinical effects of anti-EGFR antibody therapy than direct sequencing $[38,39]$, and it has also been reported that such mutation testing is useful for identifying true responders to cetuximab [40]. It should be noted that anti-EGFR monoclonal antibodies have been registered for treatment on the basis of results obtained using highly sensitive techniques of KRAS mutation testing in mCRCs [21, 103-106] and lung cancers [107]. Thus, high-sensitivity KRAS detection methods improve the prediction of benefit from targeted therapy, thereby justifying their use for routine KRAS testing.

Even in microdissected tumor material, mutant sequences in DNA isolate can be rare, and more sensitive methods than direct sequencing may be required for mutation analysis. One can imagine that a perfect approach would be the combination of manual microdissection (under the microscope) with high-sensitivity (1\% mutants in a $99 \%$ wild-type background limit of detection) methods for KRAS mutation testing. For example, if a microdissected material contains approximately $90 \%$ cancer cells, a subpopulation of approximately $1-2 \%$ of mutant cells can be detected. The requirement of such a high level of sensitivity in detecting mutant tumor cells does not seem exceptional if we consider that, to predict the response to hormonal therapy in breast cancer, an ER/PR positive tumor cell level as low as $1 \%$ is required to expect a significant clinical response [108].

\section{Diagnostic assays for KRAS mutation testing, with the CE-IVD mark}

After December 7, 2003, in vitro diagnostic (IVD) assays offered for sale in EU member countries are required to conform to IVD Directive requirements (98/79/EC) and to be CE-IVD-marked [109]. Tests without the CE-IVD mark are only acceptable for research. In the USA, similar but more restrictive FDA regulations have been in effect for many years. The CE-IVD mark guarantees that the product achieved the performance stated by the manufacturer on a variety of test parameters, such as limits of detection, analytical sensitivity and specificity, reproducibility/repeatability, and potential interfering and cross-reacting substances [110]. Nevertheless, it is surprising that, despite the EU regulations, direct sequencing and other "in-house" developed techniques were the most frequently used methods for clinical $K R A S$ testing, as shown by the results of ESP-EQA 2011 program, in which the competence of participating laboratories (mainly from member states of the European Union) in providing clinically useful reports was assessed [111]. To the best of our knowledge, there are currently 12 commercially available CE-IVD-marked KRAS mutation kits available in Europe for diagnostic use that can be divided into three categories: realtime PCR-based, sequencing-based and DNA hybridization-based tests. The pros and cons of these assays are briefly described below.

TheraScreen PCR and Pyro. The TheraScreen PCR (earlier DxS, now a Qiagen company) was the first clinically validated, CE-IVD-certified (2009) and FDA-approved (and currently the only commercially available KRAS test that is FDA-approved - for use on the Rotor-Gene Q instrument; 2012) diagnostic kit for the assessment of tumor-specific mutations in patients with CRC. It is a frequently used commercial KRAS test in Europe and the USA. In the ESP KRAS EQA scheme 2011 , this kit was used by $23 \%$ of participants [111]. The kit detects six mutations in codon 12 and one mutation in codon 13 of the KRAS oncogene (Table I). The TheraScreen PCR kit (Qiagen, Manchester, UK) combines two methods, namely: ARMS (Amplification Refractory Mutation System) and Scorpions in real-time PCR reactions. In these PCR reactions, matched (mutant-specific) primers are efficiently amplified compared with mismatched primers (only low-level background amplification occurs). The real-time PCR assay is used to assess the quantity of mutant vs. wild-type sequences in the sample. An example of data acquisition is shown in Figure 1. The TheraScreen Pyro kit is the first clinically validated, CE-IVD-marked test for pyrosequencing-based detection of KRAS mutations in codons 12, 13 and 61 dedicated for use in the PyroMark Q24 system.

Recent reports suggest that the TheraScreen PCR kit has a significantly higher sensitivity compared with sequencing, even in samples with optimal tumor cell content $\{2,61,92-94\}$. Angulo et al. [61] compared the true sensitivity of direct sequencing with that of the TheraScreen PCR kit. When the mutant DNA represented 5\% of the total DNA, the TheraScreen PCR kit detected mutations in $84 \%$ of the samples. This sensitivity was much higher than that obtained by direct sequencing, in which mutations were detected in 19 and $76 \%$ of the samples if mutant DNA constituted 5 and $30 \%$, respectively. This test increases the detection percentage of KRAS mutations by 7-25\% compared with direct sequencing [2, 92-94]. The limit of detection (LoD) of this assay (derived from cell lines) is $1 \%$ mutants in a 99\% wild-type background [112]. Small intra- and inter-lot deviations and a good concordance among the different real-time PCR systems suggested the reliability of this test for clinical use [113]. Ad- 


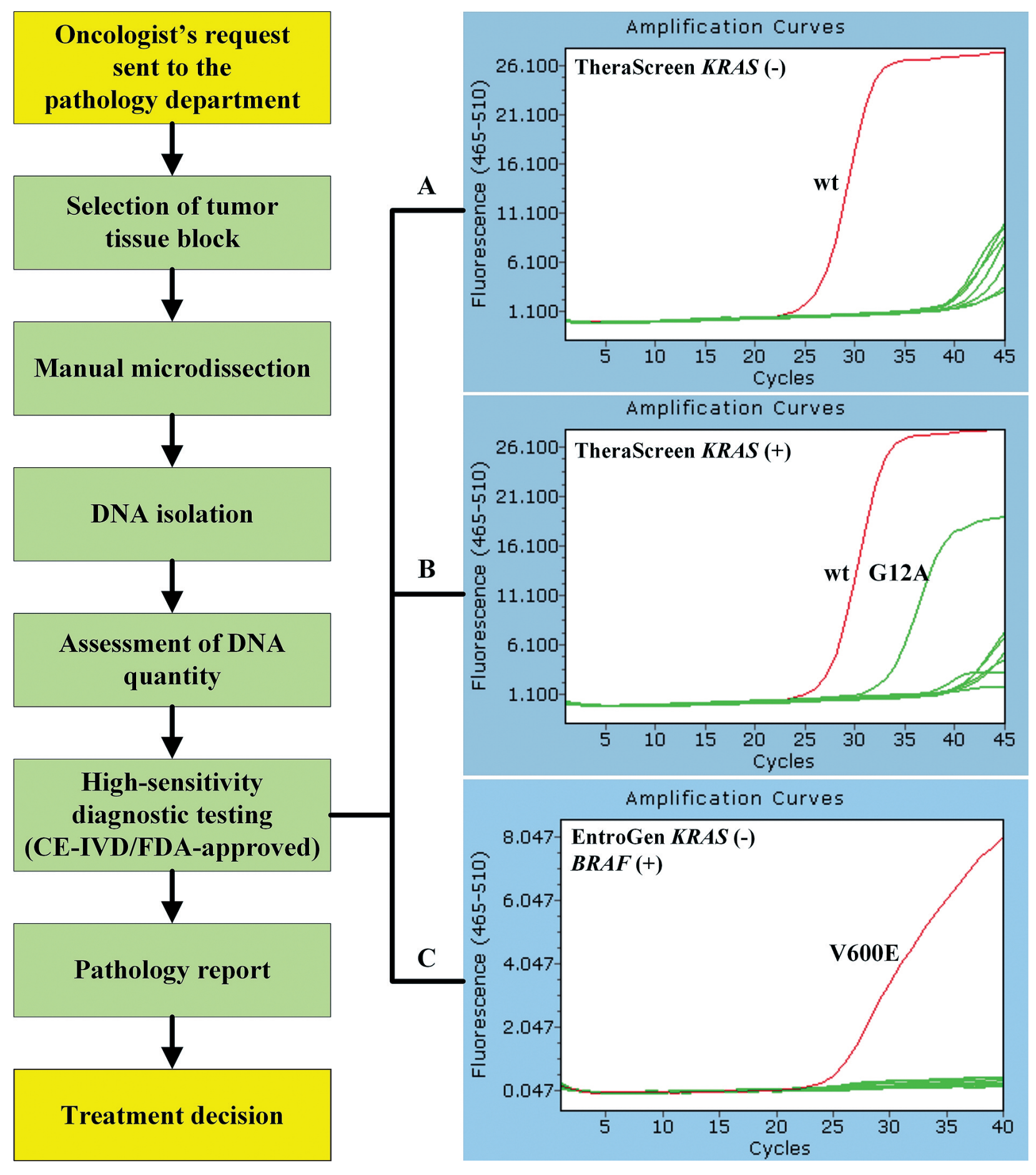

Fig. 1. Flow chart of the main stages in KRAS mutation testing for clinical use. Steps of the procedure performed by an oncologist (yellow background), and steps performed by a pathologist (green background). (A, B) An example of the raw amplification curves of $K R A S$ wild-type (A) and mutant (B) samples tested using the TheraScreen PCR mutation kit. $(\mathrm{A}, \mathrm{B})$ The curve on the farthest left (red) represents the amplification product of the wild-type (wt) control DNA (exon 4). (B) The next curve to the right (green) represents the amplification product of the mutant template (p.G12A). The small difference between the $\mathrm{Cp}$ values of the wild-type control DNA and the mutant DNA $(\triangle \mathrm{Cp}=4.7 \mathrm{cycles})$ indicates a mutation. (C) An example of the raw amplification curves (FAM fluorophore) of sample tested using the KRAS/BRAF EntroGen mutation kit. The red curve $(\mathrm{Cp}=24.96)$ represents amplification product of the $B R A F$ V600E mutant DNA (control DNA Cp $=23.68)$. 
ditional advantages of the TheraScreen PCR kit include its fast turnaround time, user-friendly software-assisted objective data interpretation, and one-step system that prevents contamination [2].

The most important limitation of this kit is the relatively high cost of the test per sample $(\sim 143$ USD [114]; 210 USD in Poland; Table I) and high DNA input requirements (Fig. 2).

PNAClamp. The PNAClamp mutation detection kit (Panagene, Daejeon, Korea) is based on peptide nucleic acid analog (PNA)-mediated real-time PCR clamping technology. The higher specificity of PNA binding to DNA, higher stability of a PNA-DNA duplex compared with the corresponding DNA-DNA

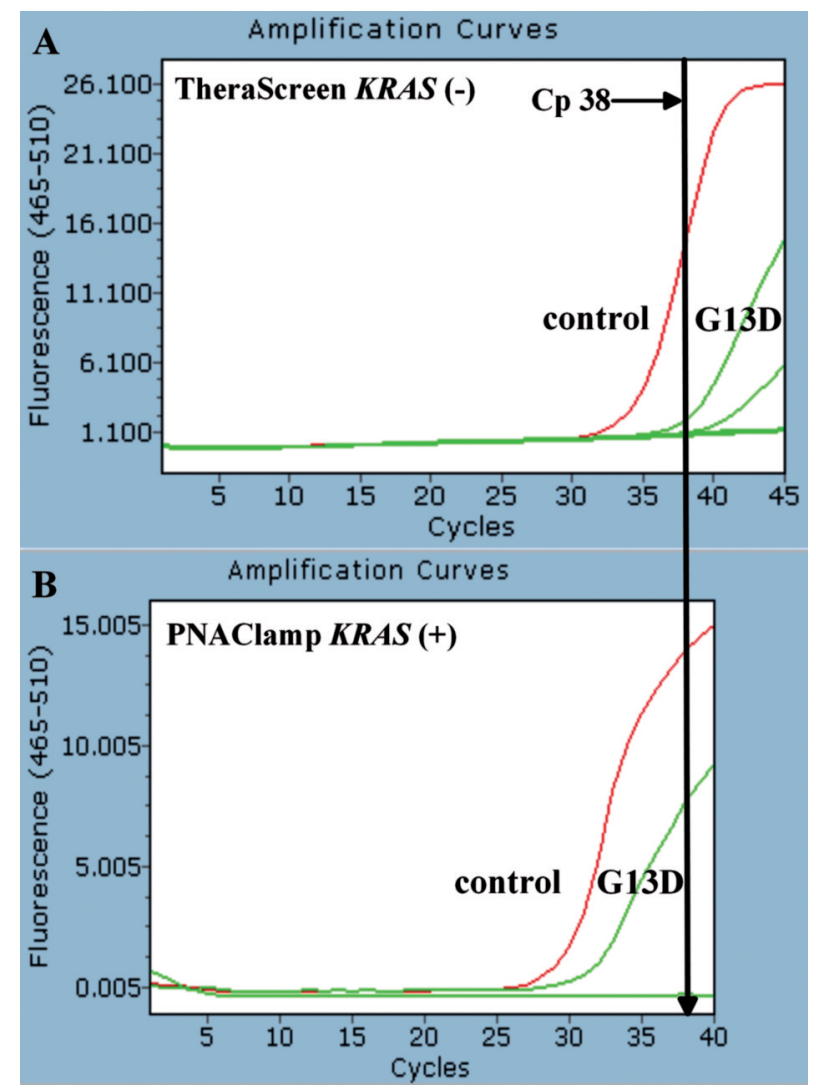

Fig. 2. An example of a discrepancy between the TheraScreen PCR kit and the PNAClamp kit for KRAS mutation testing resulting from insufficient DNA input for TheraScreen PCR kit. The same DNA input (27.3 ng total DNA) from the same patient was used for both kits. (A) The TheraScreen amplification curve for wild-type control DNA (Cp = 33.82) (red) indicates a low DNA input, thus very low-level mutations may not be detected (a warning is displayed in the test result). The next curve to the right (green) represents the amplification product for mutant DNA (p.G13D); nevertheless, if the Cp value is greater than or equal to 38 (as in this case), it is classified as negative or beyond the LoD of the kit and cannot be confidently interpreted as a mutation. (B) The same amount of DNA input is optimal for the PNAClamp kit (control $\mathrm{Cp}=29.24$; red) and a mutation in codon 13 (green) is unequivocally detected. duplex, and inefficiency of PNA to act as a primer for DNA polymerases are the bases for this technique [115]. PNA will hybridize to its complementary DNA target sequence only if the sequence is a complete match. The PNA/DNA complex effectively blocks the formation of a PCR product. On the other hand, in the case of the mutant alleles, the melting temperature of mismatched PNA-DNA hybrid is much lower than the corresponding temperature of the normal PNA-DNA hybrid. Consequently, mutated sequences are preferentially amplified, and amplification of the wild-type gene is suppressed [115, 116].

PNA-mediated PCR clamping significantly increased the percentages of detected $K R A S, B R A F$, and PIK3CA mutations compared with direct sequencing. PNA-mediated PCR clamping increased the percentage of detected KRAS mutations by $7-11 \%$ [95, 96] which implies that this method can detect minor subpopulations of tumor cells with mutant alleles. The detection of $K R A S$ mutations in tumors of low cellularity depends on the method used. Direct sequencing revealed KRAS mutations in 11 out of 114 lung cancers $(10 \%)$, whereas 10 additional mutations were detected (18\%) using PNA-mediated PCR clamping. Of these mutations, five were detected in samples with low tumor cellularity [97]. In addition, this method detected more occult metastases in lymph nodes than standard HE analysis [117]. In another study [98], the PNAClamp test detected mutations in $1 \%$ of the mutant cells, while direct sequencing barely found mutations in 20-50\% of the mutant cells. The PNAClamp test is a very sensitive method for detecting mutants in a very small amount of DNA (optimal range: $10-25 \mathrm{ng}$ of total DNA), and it is suitable for $K R A S$ mutation testing in small biopsy specimens (Fig. 2) [88, 98, 118].

The most important limitation of this kit is its inability to determine type of mutation in codon 12 .

StripAssay. A completely different type of test is the StripAssay (Vienna Labs, Vienna, Austria). This test combines mutant-enriched PCR based on PNA clamping and reverse-hybridization to nitrocellulose test strips containing specific probes for the different mutations, immobilized as an array of parallel lines. Bound biotinylated sequences are detected using streptavidinalkaline phosphatase and color substrates with a LoD of $1 \%$ mutants in a $99 \%$ wild-type background [119]. Fifteen percent of the samples that were identified as $K R A S$-positive by this test were diagnosed as wild-type by direct sequencing [120]. This test only requires a water bath, fluorometer and thermocycler. Today, it is difficult to imagine the laboratory of molecular pathology that would not be equipped with these devices. The StripAssay test detects eight mutations in codon 12 and two mutations in codon 13 of the KRAS oncogene (Table I). It is difficult to explain why two very rare mutations (p.G12I and 
p.G12L) described in only five CRCs (according to the COSMIC database v60) are detected by this test, but other, much more frequent mutations are not.

The assay procedure is labor intensive $(\sim 6 \mathrm{~h})$, because it requires several reaction steps: amplification, hybridization, detection, and washing. Nevertheless, the assay can be performed with standard laboratory equipment; therefore, this approach appears to be an interesting alternative to methods currently in use for the detection of KRAS mutations in DNA isolated from FFPE tissue [120].

Cobas. This is a TaqMelt-based real-time PCR assay designed to detect the presence of $21 \mathrm{KRAS \textrm {mu } -}$ tations in codons 12,13 , and 61 (Table I) with a LoD of approximately $5 \%$ mutants in a $95 \%$ wild-type background [110]. Mutation detection is achieved by melting curve analysis, using the Cobas 4800 System (Roche, Branchburg, NJ, USA) with automated result interpretation software. This test is highly reproducible between different clinical laboratories (98\% concordant results), requires $100 \mathrm{ng}$ of total DNA input and is more sensitive than both sequencing and the TheraScreen test [121]. The additional 12 mutations detected by the Cobas test, compared with the TheraScreen kit, represent approximately $2 \%$ of all KRAS mutations. However, recent studies suggest that codon 61 mutations may be more prevalent than reflected in the COSMIC data $[122,123]$.

The most important limitation of this test is the need for dedicated equipment.

Surveyor. This technology is based on a mismatch-specific DNA endonuclease from celery (Surveyor nuclease), which cleaves with high specificity at the 3'side of any mismatch site in both DNA strands, including all base substitutions and insertion/deletions up to at least 12 nucleotides. Subsequently, DNA fragments are analyzed with the WAVE HS System [124]. The Surveyor kit (Transgenomic, Omaha, USA) detects all mutations in exon 2 of the KRAS gene (Table I) with a LoD of $1 \%$ mutants in a $99 \%$ wildtype background [125]. Sequencing is required to confirm base changes.

The most important limitation of this test is the need for dedicated equipment.

LightMix. This kit (TIB Molbiol, Berlin, Germany) uses real-time PCR clamping technology and the melting curve method, with a LoD of $1 \%$ mutants in a $99 \%$ wild-type background. Whitehall et al. [126] reported that this kit detected a higher number of mutations (59.5\%) in FFPE tissue compared with fresh-frozen samples $(38.8 \%)$. They also found incorrect KRAS mutation types in $27 \%$ of the samples. Whitehall et al. [126] concluded that although this kit performed reasonably well with frozen tissue DNA, it yielded an unacceptably high frequency of false-positive results with FFPE samples.

\section{Other (recently developed) assays}

EntroGen. This kit (Tarzana, CA, USA) (Fig. 1.) is based on the ARMS-PCR method and detects $11 \mathrm{mu}$ tations (Table I) of the KRAS gene, with a LoD of $1 \%$ mutants in a $99 \%$ wild-type background. This test increased the detection percentage of $K R A S$ mutations by $3 \%$ compared with direct sequencing [99].

RealQuality RI-KRAS MuST. This test (Ab Analitica, Padua, Italy) detects the 7 most frequent mutations (Table I) in the KRAS gene using real-time sequence-specific primer PCR assay. The LoD is $1 \%$ mutants in a $99 \%$ wild-type background [100]. This test increases the detection percentage of KRAS mutation by $9 \%$ compared with direct sequencing [100].

Currently there are no published scientific reports on the results of KRAS mutation testing in CRCs for the following three assays (kits). (1) Hybcell Oncogenes Tissue plexA (Anagnostics Bioanalysis, St. Valentin, Austria) is based on compact sequencing and principles of microarrays (called hybcell arrays). Processing is performed in a hyborg device. While traditional arrays are printed on slides, the hybcell arrays are composed of primers that are immobilized on the surface of a cylinder. The test detects 7 common mutations (Table I) with a LoD of 1-5\% mutants in a 95-99\% wild-type background. The extended version of the test includes an additional $25 \mathrm{KRAS}$ mutations in codons 13, 61, and 146 and is under development. (2) Devyser (Devyser, Hägersten, Sweden) uses multiplex allelespecific PCR amplification for the identification of 12 $K R A S$ mutations (Table I). The LoD is $3 \%$ mutants in a $97 \%$ wild-type background, according to the manufacturer's instructions. The PCR products are analyzed using a capillary electrophoresis genetic analyzer. (3) AmoyDx (Amoy Diagnostics, Xiamen, China) is based on the ARMS-PCR method and detects the 7 most common activating mutations (Table I) of the KRAS gene in cancer tissue. The LoD is $1 \% \mathrm{mu}$ tants in a $99 \%$ wild-type background, according to the manufacturer's instructions.

\section{Comparison of $K R A S$ diagnostic assays}

Data comparing different diagnostic assays (CEIVD-marked) for $K R A S$ mutation analysis are limited. A 95\% concordance between the TheraScreen and StripAssay tests [127] as well as a $98 \%$ concordance between the TheraScreen and EntroGen tests [99] was reported. Bando et al.'s [2] study, which mimicked a real situation in a clinical genetic laboratory, demonstrated high overall agreement between the TheraScreen and StripAssay tests. However, they noted an excess of $K R A S$ mutations found by the StripAssay test compared with the TheraScreen test, and they favored the interpretation that the StripAssay test exhibits a higher false-positive rate. 
In our view, the literature supports the statement that currently the final choice of CE-IVD-marked $K R A S$ mutation testing kit is largely dependent on the laboratory equipment, experience and test cost. To compare the test cost per sample we obtained price quotes for kits available in Poland (August 2012). The results are shown in Table I.

Unfortunately, the cost per sample may depend on both the type of kit used and on the country where the kit is sold. For example, the cost per sample for the TheraScreen test is about USD 143 [114]. However, in Poland, the cost per sample of the same test is about USD 210 (kit cost obtained from Syngen Biotech, distributor of Qiagen in Poland). The high cost makes it difficult to use this test in routine clinical practice.

The number of commercially available diagnostic tests (CE-IVD-marked) will be increasing very rapidly. Real-time PCR-based methods are simple and sensitive, and will therefore be useful for molecular tests of predictive clinical significance performed in the molecular laboratories of pathology departments. Further studies by independent researchers are needed to compare these tests, identify their advantages and disadvantages and suggest recommendations.

\section{KRAS Quality Assurance Programs}

In order to demonstrate competence and expertise in molecular testing (as with all other laboratory tests), quality assurance programs based on scientific evidence are needed. There are two basic types of responsibility that are different but complementary, namely responsibility for the clinical (pathological) report and responsibility for the technical aspects of the laboratory procedure. Both types of responsibility can be assessed by external quality assurance (EQA) programs. EQA programs should be preceded by the publication of the appropriate guidelines for a particular test by scientific professional societies. Such guidelines have already been published for KRAS mutation testing [46, 62].

External quality assessment is regarded as one of the essential steps in the validation of clinical tests [128]. Therefore, we believe that an evidence-based approach requires that laboratories performing $K R A S$ tests (and other molecular predictive tests of clinical significance) be validated by EQA programs. Somatic mutation tests containing predictive information and thus of therapeutic consequences should be CE-IVD/FDA approved, as has already been done with several commercially available kits for testing $K R A S$ mutations (see above). In this respect, the guidelines of the European Society of Pathology would aid in the selection of specific technologies for routine KRAS testing in different countries [59].
There is a need for EQA programs because:

1) Data comparing different $K R A S$ mutation assays are limited.

2) Most but not all assays provide accurate results [129].

3) Currently, several commercially available assays are in vitro diagnostic-certified for the detection of somatic KRAS mutations in clinical practice and Conformité Européenne (CE)-marked. These assays can be easily used in molecular laboratories of pathology departments but their performance should be rigorously monitored.

4) An EQA program provides an opportunity for laboratories to evaluate their performance in KRAS testing and to compare it with that of other laboratories.

5) An EQA program may accelerate the harmonization and unification of KRAS mutation result reports to ensure that the reports are informative for oncologists and patients.

6) Participation in an EQA program may help to identify errors in genotyping and develop methods to eliminate them. The findings of the first phase of the development of a European EQA scheme for $K R A S$ testing, in collaboration with the European Society of Pathology showed that only ten out of 13 laboratories labeled all 14 test cases correctly; the other laboratories made one to four mistakes. In addition, the laboratories involved in that test were selected based on their prominent position in the field and all but one frequently performed $K R A S$ mutation testing for diagnostic purposes [47]. In another study, an evaluation of the concordance between $K R A S$ assays performed by 6 different laboratories that tested $20 \mathrm{CRCs}$ showed that consensus scores of $100 \%$ and $\geq 83 \%$ (in all or $5 / 6$ laboratories) were reached in only $11 / 20(55 \%)$ and $17 / 20$ (85\%) cases, respectively [130]. The main weakness of this study compared with other reports [129, 131] was that laboratories analyzed $K R A S$ mutations from centrally isolated DNA but not from tumor sections on glass slides. Thus, the results did not mimic clinical testing procedures. In general, EQA programs validate the expertise of a pathology laboratory in performing particular molecular tests and also provide means for improvement. For example, although $10-15 \%$ of the laboratories made unacceptable mistakes during the first round of ESP KRAS EQA scheme, after feedback, the labs performed significantly better [58].

7) A list of departments/laboratories that successfully passed the ESP KRAS EQA scheme maintained on the ESP website and on websites of the National Societies of Pathology/Oncology (similar to the Italian AIOM and SIAPEC websites [62]) will help oncologists to choose the appropriate laboratory for $K R A S$ mutation testing. Additionally, this information may help the appropriate institutions 
make decisions concerning reimbursement for the cost of the test.

Thus, we believe that to achieve universal, high-quality standards for KRAS mutation testing and reporting, i.e., to ensure consistency and accuracy of results, an evidence-based approach requires validation of the performance of KRAS mutation testing by various laboratories through EQA programs. In several European countries (Germany, France, Italy, Spain, Sweden, The Netherlands, and the United Kingdom), national KRAS EQA programs have been organized under the auspices and supervision of the National Associations of Pathology and Oncology [47, 59]. Four years ago, the European Society of Pathology, as an international independent body, initiated a European KRAS EQA scheme $[46,47,63]$ in which laboratories that performed the tests could participate irrespective of the DNA extraction method and KRAS testing method used. The ESP KRAS EQA scheme evaluated the correct identification of KRAS mutations, percentage of tumor cells and reporting of results. The main purpose of this EQA scheme is to assess the quality of $K R A S$ testing. An additional but equally important aim is to provide a means for improvement. The findings of the 2011 ESP KRAS EQA scheme showed that 124 laboratories from 29 countries participated and $72 \%$ reported all 10 genotypes correctly, including (for the first time) four laboratories from Poland [132]: 1. Maria Skłodowska-Curie Memorial Cancer Center and Institute of Oncology; 2. Jagiellonian University Medical College, Chair of Pathology; 3. Oncogene Diagnostics; 4. Pomeranian Medical University, Department of Pathology.

\section{Revealing targets for personalized targeted therapy is the pathologist's domain}

We would like to stress that we share the views of Silke Lassmann and Martin Werner who recently stated that: "...the expertise in morphologically- and molecular-based analyses of human tissue specimens is the pathologist's treasure and will be of utmost clinical relevance in terms of personalized medicine" [133]. The development of personalized targeted therapy is difficult because of the complex network of interactions between multiple molecular pathways $[134,135]$. Molecular alterations in these signaling pathways are just beginning to be understood in the context of therapeutic response. Pathologists are increasingly involved in the analyses of molecular signaling pathways to reveal targets of personalized targeted therapy, especially now in an era where mutation-specific antibodies useful in targeted therapy are ante portas (at the door) [136]. Personalized medicine means "The right drug, the right dose, for the right patient, at the right time" [137], i.e., the matching of a particular therapy to specific molecular features of a tumor. However, prior to the administration of targeted drugs to suitable patients, predictive molecular or immunohistochemical diagnostic tests must be conducted for both medical and economic reasons (because most targeted drugs are very expensive). As outlined above, the development of highly sensitive, simple, reliable, rapid, and compatible with FFPE tissue $K R A S$ mutation assays, instead of adapting tissue sampling and processing to research-derived molecular biology protocols, proved to be clinically useful.

$K R A S$ testing may be regarded as a testing ground indicating how pathologists of tomorrow should embrace effectively molecular technologies for the benefit of cancer patients. As outlined above, pathologists have the knowledge and expertise to identify particular gene mutations using the appropriate available molecular tests. In addition, the ESP has developed an EQA scheme to validate the expertise of the laboratories that perform the molecular tests and confirm that they are competent in this field. Indeed, this is an example of evidence-based diagnostics in action.

While the clinical effectiveness of some targeted therapies (including cetuximab for the first-line chemotherapy of $\mathrm{mCRC}$ ) has been proven, the cost/benefit ratio of such treatments is still a matter of debate $[138,139]$. There are currently no standards for the timing of KRAS mutation testing in CRC patients. Although performing KRAS testing on all CRCs at the time of surgery would be advisable (similarly to ER/PR HER2 testing in breast cancer), it may currently be difficult to defend such an approach from a cost/effective point of view. In France, the National Cancer Institute allocated $€ 2.5$ million for $K R A S$ mutation screening only in $\mathrm{mCRC}$ patients, to the 2008 budget [140]. It seems reasonable to expect and suggest that the timing of KRAS mutation testing in CRC patients should depend on the likelihood of metastatic disease in a patient with CRC at the time of operation. Postoperative material from high-risk patients could be tested, due to increased likelihood of the need to establish their KRAS mutation status [31]. In any case, KRAS mutation testing should be performed at the time of diagnosis of metastatic CRC $[25,31]$.

\section{Conclusions}

Pathologists should not be afraid of new molecular technologies because only those simplified to "kits" are currently certified for clinical purposes (and can easily be implemented). Sophisticated but very expensive molecular technologies (next generation sequencing and whole genome analysis) are currently only utilized in research. When those technologies are simplified and become much less expensive, they will also be accommodated by those pathologists who are familiar with the molecular tests now required in clinical oncology practice. Integrated histological diagnosis, en- 
riched by predictive information provided by molecular assessments, is nothing new to pathologists; what is new is the level of precision of predictive information provided by molecular analyses and the cost of molecular tests and targeted treatments. KRAS testing is just an example of a molecular test required for the implementation of targeted therapy in a particular patient population. Pathologists must be ready to perform the appropriate molecular and immunohistochemical tests to facilitate the treatment decisions made by oncologists for the benefit of patients.

In conclusion, based on the existing literature and our own experience we would like to make the following recommendations:

1. KRAS mutation testing (and other molecular tests of clinical predictive significance) should be performed by molecular laboratories in the pathology departments. This is because pathologists are responsible for the final pathology reports of CRCs, which should include predictive information. Sending paraffin blocks away for testing is not in the best interest of patients and is therefore not an optimal solution.

2. One of the commercially available CE-IVD-marked or FDA-approved "kits" should be used for KRAS mutation testing. The use of "in-house-developed methods" is not an optimal solution and should be avoided.

3. The sensitivity of direct sequencing for the analysis of $K R A S$ mutations in FFPE tumor samples seems to be too low to enable its use as a routine clinical test. The use of direct sequencing is not an optimal solution and should be avoided because, with this method, up to approximately $25 \%$ of patients selected for anti-EGFR therapy will not benefit.

4. Laboratories in the European Union performing KRAS mutation testing for diagnostic (predictive) purposes should periodically and continuously participate in the ESP KRAS EQA scheme - a program organized by an independent international body. Participation should be obligatory. The previous experiences of existing national EQA programs should be exploited and utilized by organizers of the ESP $K R A S$ EQA scheme to reach a consensus on this issue, which has very important consequences for patients, oncologists and pathologists.

\section{Conflict of interest}

The authors declare that they have no conflict of interest.

\section{References}

1. Domagala P, Huzarski T, Lubinski J, et al. Immunophenotypic predictive profiling of BRCA1-associated breast cancer. Virchows Arch 2011; 458: 55-64

2. Bando I, Cillero L, Sanz-Ortega J, et al. Study of KRAS new predictive marker in a clinical laboratory. Clin Transl Oncol 2012 [Epub ahead of print].
3. Wang HL, Lopategui J, Amin MB, Patterson SD. KRAS mutation testing in human cancers: the pathologist's role in the era of personalized medicine. Adv Anat Pathol 2010; 17: 23-32.

4. Bedeir A, Krasinskas AM. Molecular diagnostics of colorectal cancer. Arch Pathol Lab Med 2011; 135: 578-587.

5. Malapelle U, Bellevicine C, Salatiello M, et al. Sanger sequencing in routine KRAS testing: a review of 1720 cases from a pathologist's perspective. J Clin Pathol 2012; 65: 940-944.

6. Tai CJ, Chang CC, Jiang MC, et al. Clinical-pathological correlation of $\mathrm{K}$-Ras mutation and ERK phosphorylation in colorectal cancer. Pol J Pathol 2012; 63: 93-100.

7. Wójcik P, Kulig J, Okoń K, et al. KRAS mutation profile in colorectal carcinoma and novel mutation-internal tandem duplication in KRAS. Pol J Pathol 2008; 59: 93-96.

8. Neumann J, Zeindl-Eberhart E, Kirchner T, Jung A. Frequency and type of KRAS mutations in routine diagnostic analysis of metastatic colorectal cancer. Pathol Res Pract 2009; 205: 858862.

9. Forbes SA, Bindal N, Bamford S, et al. COSMIC: mining complete cancer genomes in the Catalogue of Somatic Mutations in Cancer. Nucleic Acids Res 2011; 39: D945-950.

10. Harari PM, Allen GW, Bonner JA. Biology of interactions: antiepidermal growth factor receptor agents. J Clin Oncol 2007; 25: 4057-4065.

11. Blum R, Kloog Y. Tailoring Ras-pathway-inhibitor combinations for cancer therapy. Drug Resist Updat 2005; 8: 369-380.

12. Takai Y, Sasaki T, Matozaki T. Small GTP-binding proteins. Physiol Rev 2001; 81: 153-208.

13. Normanno N, Tejpar S, Morgillo F, et al. Implications for KRAS status and EGFR-targeted therapies in metastatic CRC. Nat Rev Clin Oncol 2009; 6: 519-527.

14. Grossmann AH, Samowitz WS. Epidermal growth factor receptor pathway mutations and colorectal cancer therapy. Arch Pathol Lab Med 2011; 135: 1278-1282.

15. Moroni M, Veronese S, Benvenuti S, et al. Gene copy number for epidermal growth factor receptor (EGFR) and clinical response to antiEGFR treatment in colorectal cancer: a cohort study. Lancet Oncol 2005; 6: 279-286.

16. Lièvre $\mathrm{A}$, Bachet $\mathrm{JB}$, Le Corre $\mathrm{D}$, et al. KRAS mutation status is predictive of response to cetuximab therapy in colorectal cancer. Cancer Res 2006; 66: 3992-3995.

17. Di Fiore F, Blanchard F, Charbonnier F, et al. Clinical relevance of KRAS mutation detection in metastatic colorectal cancer treated by Cetuximab plus chemotherapy. Br J Cancer 2007; 96: 1166-1169.

18. Khambata-Ford S, Garrett CR, Meropol NJ, et al. Expression of epiregulin and amphiregulin and $\mathrm{K}$-ras mutation status predict disease control in metastatic colorectal cancer patients treated with cetuximab. J Clin Oncol 2007; 25: 3230-3237.

19. Allegra CJ, Jessup JM, Somerfield MR, et al. American Society of Clinical Oncology provisional clinical opinion: testing for KRAS gene mutations in patients with metastatic colorectal carcinoma to predict response to anti-epidermal growth factor receptor monoclonal antibody therapy. J Clin Oncol 2009; 27 : 2091-2096.

20. Karapetis CS, Khambata-Ford S, Jonker DJ, et al. K-ras mutations and benefit from cetuximab in advanced colorectal cancer. N Engl J Med 2008; 359: 1757-1765.

21. Amado RG, Wolf M, Peeters M, et al. Wild-type KRAS is required for panitumumab efficacy in patients with metastatic colorectal cancer. J Clin Oncol 2008; 26: 1626-1634.

22. De Roock W, Claes B, Bernasconi D, et al. Effects of KRAS, BRAF, NRAS, and PIK3CA mutations on the efficacy of cetuximab plus chemotherapy in chemotherapy-refractory metastatic colorectal cancer: a retrospective consortium analysis. Lancet Oncol 2010; 11: 753-762. 
23. Brand TM, Wheeler DL. KRAS mutant colorectal tumors: past and present. Small GTPases 2012; 3: 34-39.

24. College of American Pathologists. POET Report: perspectives on emerging technology: KRAS testing for colorectal cancer. http://www.cap.org/apps/docs/committees/technology/KRAS.pdf. Published September 2009. Accessed August 22, 2012.

25. National Comprehensive Cancer Network. NCCN clinical practice guidelines in oncology: colon cancer V3.2012. http://www.nccn.org/professionals/physician_gls/pdf/colon.pdf. Accessed August 22, 2012.

26. Dotti I, Bonin S, Basili G, Faoro V. Formalin-Free Fixatives. In: Guidelines for Molecular Analysis in Archive Tissues. Stanta G (ed.). Springer-Verlag, Berlin Heidelberg 2011; 13-18.

27. Nietner T, Jarutat T, Mertens A. Systematic comparison of tissue fixation with alternative fixatives to conventional tissue fixation with buffered formalin in a xenograft-based model. Virchows Arch 2012; 461: 259-269.

28. Baas JM, Krens LL, Guchelaar HJ, et al. Concordance of predictive markers for EGFR inhibitors in primary tumors and metastases in colorectal cancer: a review. Oncologist 2011; 16: 12391249.

29. Artale S, Sartore-Bianchi A, Veronese SM, et al. Mutations of KRAS and BRAF in primary and matched metastatic sites of colorectal cancer. J Clin Oncol 2008; 26: 4217-4219.

30. Boissière-Michot F, Lopez-Crapez E, Frugier H, et al. KRAS genotyping in rectal adenocarcinoma specimens with low tumor cellularity after neoadjuvant treatment. Mod Pathol 2012; 25: 731-739.

31. Ross JS. Clinical implementation of KRAS testing in metastatic colorectal carcinoma: the pathologist's perspective. Arch Pathol Lab Med 2012; 136: 1298-1307.

32. Hunt JL, Finkelstein SD. Microdissection techniques for molecular testing in surgical pathology. Arch Pathol Lab Med 2004; 128 : 1372-1378.

33. Ogino S, Kawasaki T, Brahmandam M, et al. Sensitive sequencing method for KRAS mutation detection by Pyrosequencing. J Mol Diagn 2005; 7: 413-421.

34. Warth A, Penzel R, Brandt R, et al. Optimized algorithm for Sanger sequencing-based EGFR mutation analyses in NSCLC biopsies. Virchows Arch 2012; 460: 407-414

35. Jimeno A, Messersmith WA, Hirsch FR, et al. KRAS mutations and sensitivity to epidermal growth factor receptor inhibitors in colorectal cancer: practical application of patient selection. J Clin Oncol 2009; 27: 1130-1136.

36. Aubin F, Gill S, Burkes R, et al. Canadian Expert Group consensus recommendations: KRAS testing in colorectal cancer. Curr Oncol 2011; 18: e180-184.

37. Molinari F, Felicioni L, Buscarino M, et al. Increased detection sensitivity for KRAS mutations enhances the prediction of antiEGFR monoclonal antibody resistance in metastatic colorectal cancer. Clin Cancer Res 2011; 17: 4901-4914.

38. Bando H, Yoshino T, Tsuchihara K, et al. KRAS mutations detected by the amplification refractory mutation system-Scorpion assays strongly correlate with therapeutic effect of cetuximab. Br J Cancer 2011; 105: 403-406.

39. Malapelle U, Carlomagno C, Salatiello M, et al. KRAS mutation detection by high-resolution melting analysis significantly predicts clinical benefit of cetuximab in metastatic colorectal cancer. Br J Cancer 2012; 107: 626-631.

40. Kimura T, Okamoto K, Miyamoto H, et al. Clinical benefit of high-sensitivity KRAS mutation testing in metastatic colorectal cancer treated with anti-EGFR antibody therapy. Oncology 2012; 82: 298-304.

41. Marchetti A, Milella M, Felicioni L, et al. Clinical implications of KRAS mutations in lung cancer patients treated with tyrosine kinase inhibitors: an important role for mutations in minor clones. Neoplasia 2009; 11: 1084-1092.
42. Giaretti W, Rapallo A, Sciutto A, et al. Intratumor heterogeneity of $\mathrm{k}$-ras and $\mathrm{p} 53$ mutations among human colorectal adenomas containing early cancer. Anal Cell Pathol 2000; 21: 49-57.

43. Albanese I, Scibetta AG, Migliavacca M, et al. Heterogeneity within and between primary colorectal carcinomas and matched metastases as revealed by analysis of $\mathrm{Ki}$-ras and $\mathrm{p} 53$ mutations. Biochem Biophys Res Commun 2004; 325: 784-791.

44. Losi L, Baisse B, Bouzourene H, Benhattar J. Evolution of intratumoral genetic heterogeneity during colorectal cancer progression. Carcinogenesis 2005; 26: 916-922.

45. Oltedal S, Aasprong OG, Møller JH, et al. Heterogeneous distribution of K-ras mutations in primary colon carcinomas: implications for EGFR-directed therapy. Int J Colorectal Dis 2011, 26: 1271-1277.

46. van Krieken JH, Jung A, Kirchner T, et al. KRAS mutation testing for predicting response to anti-EGFR therapy for colorectal carcinoma: proposal for an European quality assurance program. Virchows Arch 2008; 453: 417-431.

47. Dequeker E, Ligtenberg MJ, Vander Borght S, van Krieken JH Mutation analysis of KRAS prior to targeted therapy in colorectal cancer: development and evaluation of quality by a European external quality assessment scheme. Virchows Arch 2011; 459: $155-160$.

48. Gulley ML, Braziel RM, Halling KC, et al. Clinical laboratory reports in molecular pathology. Arch Pathol Lab Med 2007; 131 852-863.

49. Scheuner MT, Hilborne L, Brown J, et al. A report template for molecular genetic tests designed to improve communication between the clinician and laboratory. Genet Test Mol Biomarkers 2012; 16: 761-769.

50. ISO 15189:2011. Medical laboratories - Particular requirements for quality and competence. Geneva: International Organization for Standardization.

51. Plesec TP, Hunt JL. KRAS mutation testing in colorectal cancer. Adv Anat Pathol 2009; 16: 196-203.

52. College of American Pathologists. Labolatory general checklist. http://www.cap.org/apps/docs/laboratory_accreditation/checklists/laboratory general sep07.pdf. Published September 27, 2009. Accessed August 22, 2012.

53. European Molecular Genetics Quality Network. Final Report 2011 (Round 2) Pilot EQA scheme for EGFR mutation testing in non-small cell lung cancer. Published May 17, 2012.

54. Organisation for Economic Co-operation and Development. OECD guidelines for quality assurance in molecular genetic testing. http://www.oecd.org/science/biotechnologypolicies/ 38839788.pdf. Published 2007. Accessed August 22, 2012.

55. Kamel-Reid S, Zhang T, Persons DL, et al. Validation of KRAS testing for anti-EGFR therapeutic decisions for patients with metastatic colorectal carcinoma. Arch Pathol Lab Med 2012; 136 26-32.

56. Ciardiello F, Tejpar S, Normanno N, et al. Uptake of KRAS mutation testing in patients with metastatic colorectal cancer in Europe, Latin America and Asia. Target Oncol 2011; 6: 133-145.

57. Bibeau F, Louvet $C$, Afchain $P$, et al. Observational study on conditions for access to the analysis of KRAS mutation in patients with metastatic colorectal cancer receiving panitumumab treatment. Bull Cancer 2012; 99: 743-751.

58. van Krieken JH, Hoefler G. The times have changed: molecular pathology is here to stay. A commentary on: analytical performance of a PCR assay for the detection of KRAS mutations (codons 12/13 and 61) in formalin-fixed paraffin-embedded tissue samples of colorectal carcinoma, by Lee et al. In this issue. Virchows Arch 2012; 460: 129-130.

59. Moch H, Blank PR, Dietel M, et al. Personalized cancer medicine and the future of pathology. Virchows Arch 2012; 460: 3-8.

60. Dietel M, Sers C. Personalized medicine and development of targeted therapies: the upcoming challenge for diagnostic molecular pathology. A review. Virchows Arch 2006; 448: 744-755. 
61. Angulo B, García-García E, Martínez R, et al. A commercial realtime PCR kit provides greater sensitivity than direct sequencing to detect KRAS mutations: a morphology-based approach in colorectal carcinoma. J Mol Diagn 2010; 12: 292-299.

62. Normanno N, Pinto C, Castiglione F, et al. KRAS mutations testing in colorectal carcinoma patients in Italy: from guidelines to external quality assessment. PLoS One 2011; 6: e29146.

63. Bellon E, Ligtenberg MJ, Tejpar S, et al. External quality assessment for KRAS testing is needed: setup of a European program and report of the first joined regional quality assessment rounds. Oncologist 2011; 16: 467-478.

64. Thunnissen E, Bovée JV, Bruinsma H, et al. EGFR and KRAS quality assurance schemes in pathology: generating normative data for molecular predictive marker analysis in targeted therapy. J Clin Pathol 2011; 64: 884-892.

65. Kotoula V, Charalambous E, Biesmans B, et al. Targeted KRAS mutation assessment on patient tumor histologic material in real time diagnostics. PLoS One 2009; 4: e7746.

66. Rauser S, Weis R, Braselmann H, et al. Significance of HER2 low-level copy gain in Barrett's cancer: implications for fluorescence in situ hybridization testing in tissues. Clin Cancer Res 2007; 13: 5115-5123.

67. Chowdhuri SR, Xi L, Pham TH, et al. EGFR and KRAS mutation analysis in cytologic samples of lung adenocarcinoma enabled by laser capture microdissection. Mod Pathol 2012; 25: 548-555.

68. Kristiansen G. Manual microdissection. Methods Mol Biol 2010; 576: 31-38

69. Burgemeister R. Nucleic acids extraction from laser microdissected FFPE tissue sections. Methods Mol Biol 2011; 724: 117-129.

70. Burton MP, Schneider BG, Brown R, et al. Comparison of histologic stains for use in PCR analysis of microdissected, paraffin-embedded tissues. Biotechniques 1998; 24: 86-92.

71. Murase T, Inagaki H, Eimoto T. Influence of histochemical and immunohistochemical stains on polymerase chain reaction. Mod Pathol 2000; 13: 147-151.

72. Morikawa T, Shima K, Kuchiba A, et al. No evidence for interference of h\&e staining in DNA testing: usefulness of DNA extraction from h\&e-stained archival tissue sections. Am J Clin Pathol 2012; 138: 122-129.

73. Ludyga N, Grünwald B, Azimzadeh O, et al. Nucleic acids from long-term preserved FFPE tissues are suitable for downstream analyses. Virchows Arch 2012; 460: 131-140.

74. Mittempergher L, de Ronde JJ, Nieuwland M, et al. Gene expression profiles from formalin fixed paraffin embedded breast cancer tissue are largely comparable to fresh frozen matched tissue. PLoS One 2011; 6: e17163.

75. Yost SE, Smith EN, Schwab RB, et al. Identification of highconfidence somatic mutations in whole genome sequence of formalin-fixed breast cancer specimens. Nucleic Acids Res 2012; 40: e107.

76. Li J, Smyth P, Flavin R, et al. Comparison of miRNA expression patterns using total RNA extracted from matched samples of formalin-fixed paraffin-embedded (FFPE) cells and snap frozen cells. BMC Biotechnol 2007; 7: 36.

77. Chomczynski P, Sacchi N. Single-step method of RNA isolation by acid guanidinium thiocyanate-phenol-chloroform extraction. Anal Biochem 1987; 162: 156-159.

78. Okello JB, Zurek J, Devault AM, et al. Comparison of methods in the recovery of nucleic acids from archival formalin-fixed paraffin-embedded autopsy tissues. Anal Biochem 2010; 400: 110-117.

79. Turashvili G, Yang W, McKinney S, et al. Nucleic acid quantity and quality from paraffin blocks: defining optimal fixation, processing and DNA/RNA extraction techniques. Exp Mol Pathol 2012; 92: 33-43.

80. Muñoz-Cadavid C, Rudd S, Zaki SR, et al. Improving molecular detection of fungal DNA in formalin-fixed paraffin-embedded tissues: comparison of five tissue DNA extraction methods using panfungal PCR. J Clin Microbiol 2010; 48: 2147-2153.
81. Bonin S, Hlubek F, Benhattar J, et al. Multicentre validation study of nucleic acids extraction from FFPE tissues. Virchows Arch 2010; 457: 309-317.

82. Bonin S, Groenen P, Halbwedl I, Popper HH. DNA Extraction from Formalin-Fixed Paraffin-Embedded (FFPE) Tissues. In: Guidelines for Molecular Analysis in Archive Tissues. Stanta G (ed.). Springer-Verlag, Berlin Heidelberg 2011; 33-36.

83. Hlubek F, Jung A. Fast Protocol for DNA Extraction from Formalin-Fixed Paraffin-Embedded Tissues. In: Guidelines for Molecular Analysis in Archive Tissues. Stanta G (ed.). Springer-Verlag, Berlin Heidelberg 2011; 41-43.

84. Singer VL, Jones LJ, Yue ST, Haugland RP. Characterization of PicoGreen reagent and development of a fluorescence-based solution assay for double-stranded DNA quantitation. Anal Biochem 1997; 249: 228-238.

85. Boesenberg-Smith K, Pessarakli M, Wolk D. Assessment of DNA Yield and Purity: an Overlooked Detail of PCR Troubleshooting. Clin Microbiol Newsl 2012; 34: 1-6.

86. Gallagher SR. Quantitation of DNA and RNA with absorption and fluorescence spectroscopy. Curr Protoc Mol Biol 2011; Appendix 3: 3D.

87. Anderson SM. Laboratory methods for KRAS mutation analysis. Expert Rev Mol Diagn 2011; 11: 635-642.

88. Pao W, Ladanyi M. Epidermal growth factor receptor mutation testing in lung cancer: searching for the ideal method. Clin Cancer Res 2007; 13: 4954-4955.

89. Eberhard DA, Giaccone G, Johnson BE. Biomarkers of response to epidermal growth factor receptor inhibitors in Non-SmallCell Lung Cancer Working Group: standardization for use in the clinical trial setting. J Clin Oncol 2008; 26: 983-994.

90. Hoorens A, Jouret-Mourin A, Sempoux C, et al. Accurate KRAS mutation testing for EGFR-targeted therapy in colorectal cancer: emphasis on the key role and responsibility of pathologists. Acta Gastroenterol Belg 2010; 73: 497-503.

91. Turner NC, Reis-Filho JS. Genetic heterogeneity and cancer drug resistance. Lancet Oncol 2012; 13: e178-185.

92. Franklin WA, Haney J, Sugita M, et al. KRAS mutation: comparison of testing methods and tissue sampling techniques in colon cancer. J Mol Diagn 2010; 12: 43-50.

93. Pinto P, Rocha P, Veiga I, et al. Comparison of methodologies for KRAS mutation detection in metastatic colorectal cancer. Cancer Genet 2011; 204: 439-446.

94. Bando H, Tsuchihara K, Yoshino T, et al. Biased discordance of KRAS mutation detection in archived colorectal cancer specimens between the ARMS-Scorpion method and direct sequencing. Jpn J Clin Oncol 2011; 41: 239-244.

95. Kwon MJ, Lee SE, Kang SY, Choi YL. Frequency of KRAS, BRAF, and PIK3CA mutations in advanced colorectal cancers: comparison of peptide nucleic acid-mediated PCR clamping and direct sequencing in formalin-fixed, paraffin-embedded tissue. Pathol Res Pract 2011; 207: 762-768.

96. Kobunai T, Watanabe T, Yamamoto Y, Eshima K. The frequency of KRAS mutation detection in human colon carcinoma is influenced by the sensitivity of assay methodology: a comparison between direct sequencing and real-time PCR. Biochem Biophys Res Commun 2010; 395: 158-162.

97. Beau-Faller M, Legrain M, Voegeli AC, et al. Detection of KRas mutations in tumour samples of patients with non-small cell lung cancer using PNA-mediated PCR clamping. Br J Cancer 2009; 100: 985-992.

98. Jeong D, Jeong Y, Lee J, et al. Rapid and sensitive detection of KRAS mutation by peptide nucleic acid-based real-time PCR clamping: a comparison with direct sequencing between fresh tissue and formalin-fixed and paraffin embedded tissue of colorectal cancer. Korean J Pathol 2011; 45: 151-159.

99. Hancer VS, Buyukdogan M, Türkmen I, et al. Comparison of KRAS mutation tests in colorectal cancer patients. Genet Test Mol Biomarkers 2011; 15: 831-834. 
100. Marzinotto S, Sessa F, Franzoni A, et al. KRAS codons 12 and 13 mutation analysis: a comparative study between direct sequencing and a new sensitive real-time PCR assay. Sequencing 2011; Article ID 895709.

101. Lyon E, Wittwer CT. LightCycler technology in molecular diagnostics. J Mol Diagn 2009; 11: 93-101.

102. Palmirotta R, Ludovici G, De Marchis ML, et al. A comprehensive procedural approach to genotyping KRAS and BRAF from paraffin embedded tissues for diagnostic purposes. In Vivo 2012; 26: $537-547$.

103. Bokemeyer C, Bondarenko I, Makhson A, et al. Fluorouracil, leucovorin, and oxaliplatin with and without cetuximab in the first-line treatment of metastatic colorectal cancer. J Clin Oncol 2009; 27: 663-671.

104. Tol J, Koopman M, Cats A, et al. Chemotherapy, bevacizumab, and cetuximab in metastatic colorectal cancer. N Engl J Med 2009; 360: 563-572.

105. Douillard JY, Siena S, Cassidy J, et al. Randomized, phase III trial of panitumumab with infusional fluorouracil, leucovorin, and oxaliplatin (FOLFOX4) versus FOLFOX4 alone as firstline treatment in patients with previously untreated metastatic colorectal cancer: the PRIME study. J Clin Oncol 2010; 28: 4697-4705.

106. Van Cutsem E, Köhne CH, Láng I, et al. Cetuximab plus irinotecan, fluorouracil, and leucovorin as first-line treatment for metastatic colorectal cancer: updated analysis of overall survival according to tumor KRAS and BRAF mutation status. J Clin Oncol 2011; 29: 2011-2019.

107. Mok TS, Wu YL, Thongprasert S, et al. Gefitinib or carboplatinpaclitaxel in pulmonary adenocarcinoma. N Engl J Med 2009; 361: 947-957.

108. Hammond ME, Hayes DF, Dowsett M, et al. American Society of Clinical Oncology/College of American Pathologists guideline recommendations for immunohistochemical testing of estrogen and progesterone receptors in breast cancer. Arch Pathol Lab Med 2010; 134: 907-922.

109. Castle G, Blaney R. European Union Regulation of In Vitro Diagnostic Medical Devices. In: In Vitro Diagnostics: The Complete Regulatory Guide. Danzis SD, Flannery EJ (eds.). Food and Drug Law Institute, Washington D.C. 2010; 227252.

110. Lee S, Brophy VH, Cao J, et al. Analytical performance of a PCR assay for the detection of KRAS mutations (codons 12/13 and 61) in formalin-fixed paraffin-embedded tissue samples of colorectal carcinoma. Virchows Arch 2012; 460: 141-149.

111. European Society of Pathology. General report. ESP KRAS external quality assessment scheme 2011. http://kras. eqascheme.org. Published March 9, 2012.

112. Carotenuto P, Roma C, Rachiglio AM, et al. Detection of KRAS mutations in colorectal carcinoma patients with an integrated PCR/sequencing and real-time PCR approach. Pharmacogenomics 2010; 11: 1169-1179.

113. Ogasawara N, Bando H, Kawamoto Y, et al. Feasibility and robustness of amplification refractory mutation system (ARMS)-based KRAS testing using clinically available formalinfixed, paraffin-embedded samples of colorectal cancers. Jpn J Clin Oncol 2011; 41: 52-56.

114. Nordgård O, Oltedal S, Janssen EA, et al. Comparison of a PNA clamp PCR and an ARMS/Scorpion PCR assay for the detection of K-ras mutations. Diagn Mol Pathol 2012; 21: 9-13.

115. Ray A, Nordén B. Peptide nucleic acid (PNA): its medical and biotechnical applications and promise for the future. FASEB J 2000; 14: 1041-1060.

116. Thiede C, Bayerdörffer E, Blasczyk R, et al. Simple and sensitive detection of mutations in the ras proto-oncogenes using PNA-mediated PCR clamping. Nucleic Acids Res 1996; 24 : 983-984
117. Taback B, Bilchik AJ, Saha S, et al. Peptide nucleic acid clamp PCR: a novel K-ras mutation detection assay for colorectal cancer micrometastases in lymph nodes. Int J Cancer 2004; 111 : 409-414.

118. Nagai Y, Miyazawa H, Huqun, et al. Genetic heterogeneity of the epidermal growth factor receptor in non-small cell lung cancer cell lines revealed by a rapid and sensitive detection system, the peptide nucleic acid-locked nucleic acid PCR clamp. Cancer Res 2005; 65: 7276-7282.

119. Kriegshäuser G, Auner V, Schuster E, et al. KRAS mutation analysis in genomic DNA isolated from formalin-fixed paraffin-embedded ovarian tissue: evaluation of a strip-based reversehybridisation assay. J Clin Pathol 2011; 64: 252-256.

120. Ausch C, Buxhofer-Ausch V, Oberkanins C, et al. Sensitive detection of KRAS mutations in archived formalin-fixed paraffin-embedded tissue using mutant-enriched PCR and reversehybridization. J Mol Diagn 2009; 11: 508-513.

121. Gonzalez de Castro D, Angulo B, Gomez B, et al. A comparison of three methods for detecting KRAS mutations in formalinfixed colorectal cancer specimens. Br J Cancer 2012; 107 : 345-351.

122. Richman SD, Seymour MT, Chambers P, et al. KRAS and BRAF mutations in advanced colorectal cancer are associated with poor prognosis but do not preclude benefit from oxaliplatin or irinotecan: results from the MRC FOCUS trial. J Clin Oncol 2009; 27: 5931-5937.

123. Gaedcke J, Grade M, Jung K, et al. KRAS and BRAF mutations in patients with rectal cancer treated with preoperative chemoradiotherapy. Radiother Oncol 2010; 94: 76-81.

124. Qiu P, Shandilya H, D'Alessio JM, et al. Mutation detection using Surveyor nuclease. Biotechniques 2004; 36: 702-707.

125. Jänne PA, Borras AM, Kuang Y, et al. A rapid and sensitive enzymatic method for epidermal growth factor receptor mutation screening. Clin Cancer Res 2006; 12: 751-758.

126. Whitehall V, Tran K, Umapathy A, et al. A multicenter blinded study to evaluate KRAS mutation testing methodologies in the clinical setting. J Mol Diagn 2009; 11: 543-552.

127. Cavallini A, Valentini AM, Lippolis C, et al. KRAS genotyping as biomarker in colorectal cancer: a comparison of three commercial kits on histologic material. Anticancer Res 2010; 30: 5251-5256.

128. Jennings L, Van Deerlin VM, Gulley ML. Recommended principles and practices for validating clinical molecular pathology tests. Arch Pathol Lab Med 2009; 133: 743-755.

129. Oliner K, Juan T, Suggs S, et al. A comparability study of 5 commercial KRAS tests. Diagn Pathol 2010; 5: 23.

130. Tysarowski A, Fabisiewicz A, Kolasa I, et al. Validation of selected molecular methods for the mutations determination in codons 12 and 13 of K-RAS gene in five Polish oncological research centers. Onkol Prak Klin 2008; 4: 232-244.

131. Feigelson HS, Goddard KA, Johnson MA, et al. Reliability of KRAS mutation testing in metastaticcolorectal cancer patients across five laboratories. BMC Res Notes 2012; 5: 196.

132. European Society of Pathology. Who participated so far in the ESP KRAS EQA schemes with a genotyping score of $\geq 90 \%$ ? http://kras.eqascheme.org/info/public/eqa/previous_participants.xhtml. Published April 20, 2012. Accessed August 22, 2012.

133. Lassmann S, Werner M. Predictive pathology in routine diagnostics of solid tumors. Histol Histopathol 2012; 27 : 289-296.

134. Dahinden C, Ingold B, Wild P, et al. Mining tissue microarray data to uncover combinations of biomarker expression patterns that improve intermediate staging and grading of clear cell renal cell cancer. Clin Cancer Res 2010; 16: 88-98.

135. Barabási AL, Gulbahce N, Loscalzo J. Network medicine: a network-based approach to human disease. Nat Rev Genet 2011; 12: 56-68. 
136. Yu J, Kane S, Wu J, et al. Mutation-specific antibodies for the detection of EGFR mutations in non-small-cell lung cancer. Clin Cancer Res 2009; 15: 3023-3028.

137. Stricker T, Catenacci DV, Seiwert TY. Molecular profiling of cancer - the future of personalized cancer medicine: a primer on cancer biology and the tools necessary to bring molecular testing to the clinic. Semin Oncol 2011;38: 173-185.

138. Rinaldi F, George E, Adler AI. NICE guidance on cetuximab, bevacizumab, and panitumumab for treatment of metastatic colorectal cancer after first-line chemotherapy. Lancet Oncol 2012; 13: 233-234.

139. Getting personal. Nature 2011; 473: 253-254.

140. Nowak F, Soria JC, Calvo F. Tumour molecular profiling for deciding therapy-the French initiative. Nat Rev Clin Oncol 2012; 9: 479-486.

\section{Address for correspondence:}

\section{Prof. Wenancjusz Domagała, MD}

Department of Pathology

Pomeranian Medical University

Unii Lubelskiej 1

71-252 Szczecin

phone/fax +48914870032

e-mail: wenek@pum.edu.pl 